\title{
TECHNOLOGICAL PROGRESS AND ECONOMIC TRANSFORMATION
}

\author{
JEREMY GREENWOOD
}

University of Rochester

\section{ANANTH SESHADRI}

University of Wisconsin

\section{Contents}

$\begin{array}{ll}\text { Abstract } & 1226\end{array}$

$\begin{array}{lr}\text { Keywords } & 1226\end{array}$

$\begin{array}{ll}\text { 1. Introduction } & 1227\end{array}$

$\begin{array}{ll}\text { 1.1. Technological progress in the market } & 1227\end{array}$

$\begin{array}{lr}\text { 1.2. Technological progress in the home } & 1229\end{array}$

$\begin{array}{lr}\text { 1.3. The goal } & 1230 \\ & 1231\end{array}$

2. The baby bust and baby boom 1231

$\begin{array}{ll}2.1 . & 1231 \\ & 1233\end{array}$

2.2. Analysis 1233

3. The U.S. demographic transition $\quad 1238$

$\begin{array}{lr}\text { 3.1. The environment } & 1238\end{array}$

\begin{tabular}{lr} 
3.2. Analysis & 1242 \\
\hline & 1246
\end{tabular}

4. The demise of child labor $\quad 1246$

$\begin{array}{lr}\text { 4.1. The environment } & 1247\end{array}$

$\begin{array}{lr}\text { 4.2. Analysis } & 1248\end{array}$

$\begin{array}{lr}\text { 5. Engines of liberation } & 1250\end{array}$

$\begin{array}{ll}\text { 5.1. The environment } & 1252\end{array}$

$\begin{array}{ll}\text { 5.2. Analysis } & 1254\end{array}$

$\begin{array}{ll}\text { 5.3. Analysis with nondurable household products and services } & 1258\end{array}$

$\begin{array}{lr}\text { 6. Conclusion } & 1260\end{array}$

$\begin{array}{ll}\text { 7. Literature review } & 1261\end{array}$

$\begin{array}{ll}\text { 7.1. Fertility } & 1261\end{array}$

$\begin{array}{lr}\text { 7.2. The economics of household production } & 1262\end{array}$

$\begin{array}{ll}\text { 7.3. Structural change } & 1263\end{array}$

Handbook of Economic Growth, Volume 1B. Edited by Philippe Aghion and Steven N. Durlauf (C) 2005 Elsevier B.V. All rights reserved

DOI: 10.1016/S1574-0684(05)01019-1 
7.4. Child labor 1264

7.5. Female labor-force participation $\quad 1266$

$\begin{array}{lr}\text { Acknowledgements } & 1268\end{array}$

$\begin{array}{lr}\text { Appendix: } & 1268\end{array}$

A.1. Supporting calculations for Lemmas 2 and $4 \quad 1268$

$\begin{array}{ll}\text { A.2. Supporting calculations for Lemmas } 5 \text { and } 6 & 1270\end{array}$

$\begin{array}{lr}\text { References } & 1271\end{array}$

\begin{abstract}
Growth theory can go a long way toward accounting for phenomena linked with U.S. economic development. Some examples are:

(i) the secular decline in fertility between 1800 and 1980,

(ii) the decline in agricultural employment and the rise in skill since 1800 ,

(iii) the demise of child labor starting around 1900,

(iv) the increase in female labor-force participation from 1900 to 1980,

(v) the baby boom from 1936 to 1972 .
\end{abstract}

Growth theory models are presented to address all of these facts. The analysis emphasizes the role of technological progress as a catalyst for economic transformation.

\title{
Keywords
}

child labor, economic growth, educational attainment, female labor-force participation, fertility, household production theory, technological progress

JEL classification: D1, E1, J1, O3 


\section{Introduction}

Life in the 1800s. Imagine living as a typical American child in the nineteenth century. You have six brothers and/or sisters. You live in a house, outside of an urban area, with no running water, no central heating, and no electricity. Your father labors 70 hours a week in the agricultural economy. Your mother probably puts in about the same amount of time doing work at home. Less than half of your years between the ages of 5 and 20 will be devoted to school. So, perhaps you are playing in the family kitchen that contains a cast iron range, a table, and a dresser. But, more likely you are helping your parents by doing one of a litany of chores: carrying wood or water into the house, washing clothes on a scrub board or ironing them with a flat iron, looking after younger siblings, preparing meals, cleaning the house, making clothes, tending crops or animals, etc. In this era, household production is an incredibly labor-intensive process. What changed this situation? The catalyst for the ensuing economic transformation to modern day life was technological progress, both in the market and at home, or so it will be argued here.

\subsection{Technological progress in the market}

Fertility. Over the period from 1830 to 1990 real wages increased by a factor of $9-$ see Figure $1 .^{1}$ This rise was propelled by a near 7-fold increase in market-sector total factor productivity (TFP) between 1800 and 1990. Such tremendous technological advance had a dramatic impact on everyday life. As an example, consider the effect that economic progress could have had on fertility. Raising children takes time. A secular increase in real wages implies that the opportunity cost of having a child, when measured in terms of market goods, will rise. The utility value of an extra unit of market consumption relative to an extra child should fall, however, as market goods become more abundant with economic development. So long as the marginal utility of market goods falls by less than the increase in real wages fertility should decline. And so fertility did decline, from 7 kids per woman in 1800 to 2 today.

Industrialization and skilled labor. At the start of the 1800s America was largely a rural economy. Over seventy percent of workers were employed in agriculture - see Figure $2 .^{2}$ Less than 50 percent of children between the ages of 5 and 20 went to school. From 1800 to 1940 technological advance in the nonagricultural sector of the U.S. economy was twice as fast as in the agricultural sector. Furthermore, agricultural goods had a lower income elasticity than nonagricultural ones. These two facts together implied that the demand for labor in the nonagricultural sector of the economy rose relative to the demand for labor in the agricultural sector. Since the nonagricultural sector required

\footnotetext{
1 The data sources used in Figure 1 are given in Greenwood, Seshadri and Vandenbroucke (2005).

2 The enrollment rate figures come from "Historical Statistics of the United States: Colonial Times to 1970" [U.S. Bureau of the Census (1975, Series H 433)]. See Greenwood and Seshadri (2002) for the sources of the other data plotted in Figure 2.
} 


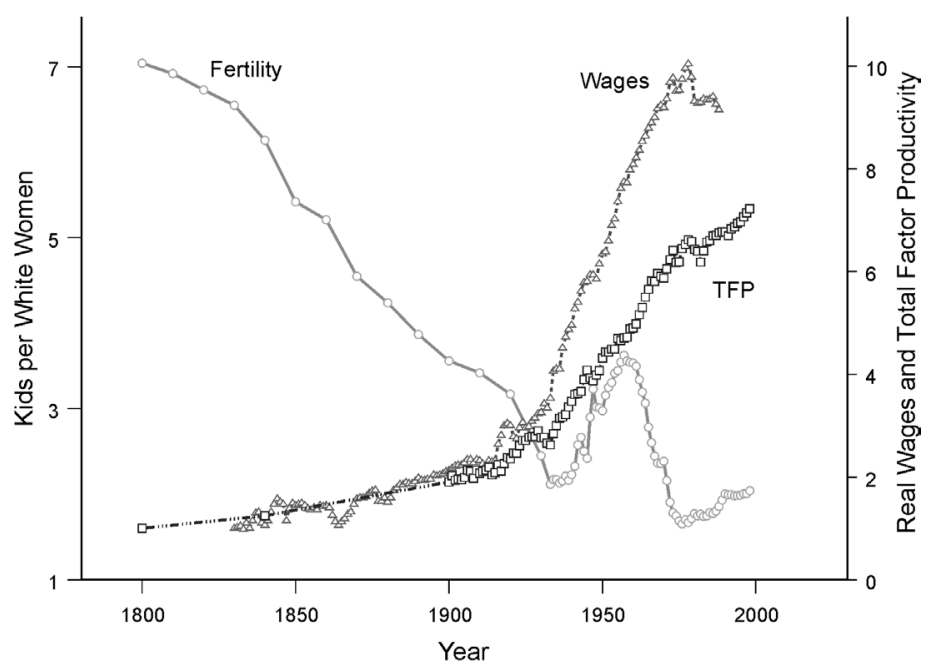

Figure 1. Technological progress in the market and fertility.
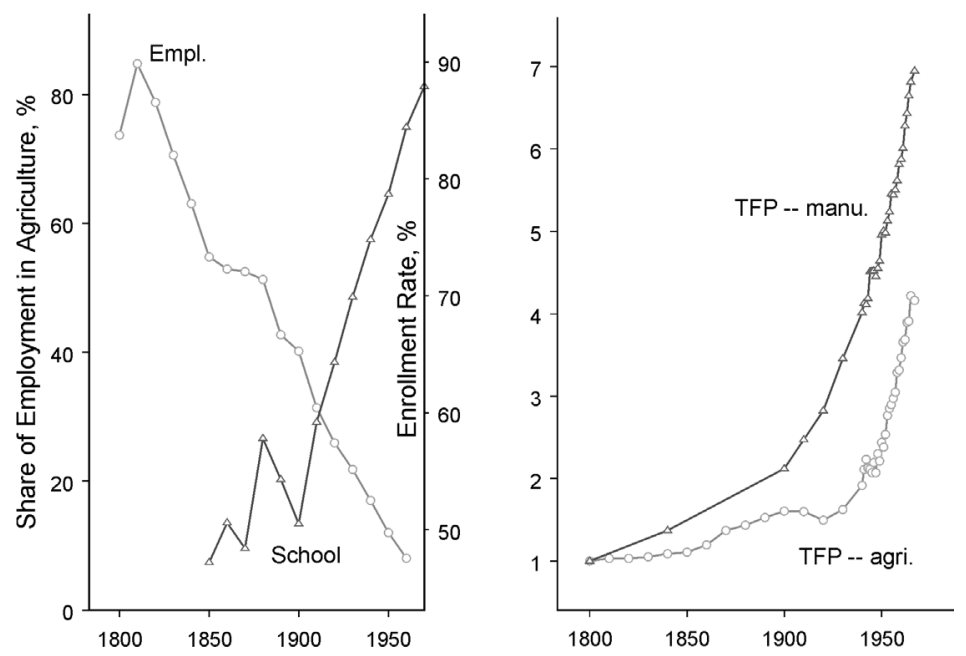

Figure 2. The decline in agriculture and the rise in skilled labor.

a more skill-intensive labor force than did the agricultural sector, the demand for skilled labor rose too.

Child labor. Children formed an important part of the labor force in the nineteenth century. Exact numbers are hard to come by, though. First, the data before 1870 is scarce. Lebergott $(1964$, p. 50) reports that 43 percent of textile workers in Massa- 
Table 1

Children aged $10-15$ as percentage of the gainfully employed

\begin{tabular}{ccccc}
\hline Year & All occupations & Agriculture & Manufacturing & Mining \\
\hline 1870 & 13.2 & 9.3 & 5.6 & 7.1 \\
1880 & 16.8 & 11.6 & 6.7 & \\
1890 & 18.1 & 11.5 & 2.8 & \\
1900 & 18.2 & 11.4 & 3.2 & 2.1 \\
1910 & 15.0 & 9.8 & 2.4 & 0.8 \\
1920 & 11.3 & 8.0 & 1.3 & $<1.0$ \\
1930 & 4.7 & 3.3 & $<1.0$ & $<1.0$ \\
\hline
\end{tabular}

Source: Lebergott (1964, p. 53).

chusetts around 1820 were children, as were 47 and 55 percent in Connecticut and Rhode Island. Second, the available figures pertain to paid labor. These statistics omit the labors of children on family farms and businesses, or around the home - the same is true for housewives of the era. The incidence of child labor rose until 1900, as Table 1 shows. At that time children made up about 20 percent of the paid labor force. It then began to decline. By 1930 child labor had vanished.

A reasonable hypothesis is that technological progress reduced the need for unskilled labor in agriculture and manufacturing. Take agriculture, for example, where the late nineteenth and early twentieth centuries saw massive improvements in agricultural technology. Two of the most important inventions were the horse-drawn harvester in the mid-nineteenth century and the tractor that began to diffuse into American farms in the early twentieth century. Mechanization of farms virtually eliminated the need for raw labor: In 1830, it would take a farmer 250-300 hours to produce 100 bushels of wheat; in 1890, 40-50 hours with the help of a horse-drawn machine; in 1930, 15-20 hours with a tractor; and in 1975, 3-4 hours with large tractors and combines. ${ }^{3}$

\subsection{Technological progress in the home}

Female labor-force participation. Just as the last 200 years have witnessed technological progress in the market sector, they have witnessed tremendous technological advance in the home sector. Since productivity numbers are not computed for the home sector, given the elusive nature of output and inputs, the evidence on technological progress is circumstantial. The household sector in the American economy was basically a cottage industry until the dawning of the Second Industrial Revolution. With the onset of the electric age a host of new appliances were ushered in: washing machines, refrigerators, etc. It took time for these new capital goods to diffuse through the econ-

${ }^{3}$ Source: U.S. Department of Agriculture. 

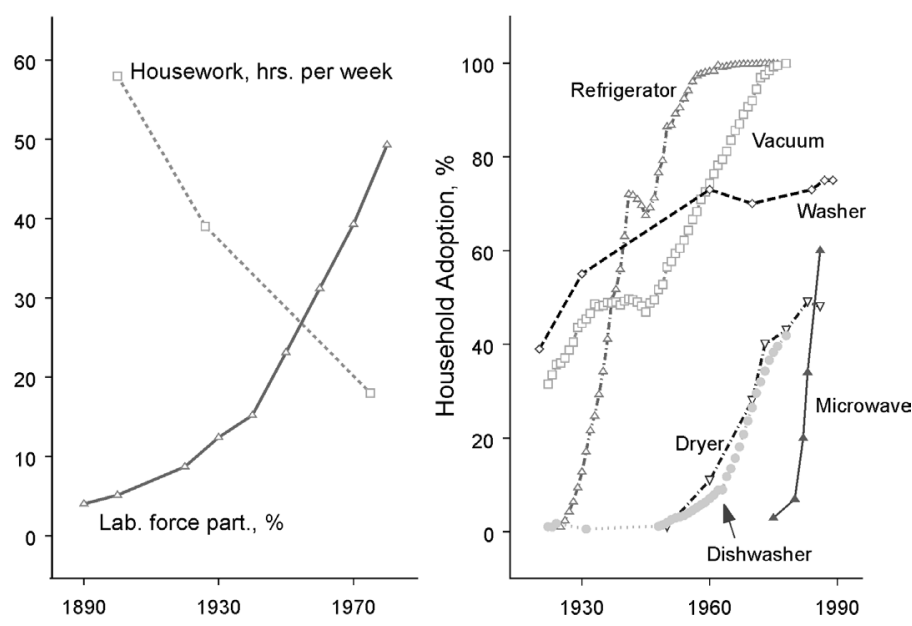

Figure 3. Technological progress in the home and female labor-force participation.

omy, as Figure 3 shows. ${ }^{4}$ At the same time, the principles of scientific management were being applied to everyday household tasks. The large table and isolated dresser that characterized a kitchen of the 1800 s were replaced by continuous countertops and built-in cabinets. This wave of technological progress in the home freed up tremendous amounts of labor - see Figure 3. The time spent on housework fell from 58 hours per week in 1900 to just 18 in 1975. Married women could now enter the labor force, and they did in droves.

Fertility. Technological progress in the household sector could also have had implications for fertility. Labor-saving household goods that ease the burden of housework will lower the cost of raising children. Fertility should rise. In fact it did; between 1936 and 1957 fertility increased by 53 percent - see Figure 1 .

\subsection{The goal}

The goal here is to persuade you that standard Solow (1956)-Ramsey (1928) growth theory can be fruitfully employed to explain these phenomena. Specifically, all of these facts can be accounted for by modifying the standard growth paradigm to incorporate fertility decisions, household production, human capital investment in children, laborforce participation, and multiple sectors. It will be argued that technological progress is the engine driving economic transformation. A selective review of the literature is provided in Section 7.

\footnotetext{
4 The data sources for the Figure 3 are provided in Greenwood, Seshadri and Yorukoglu (2005).
} 


\section{The baby bust and baby boom}

Two facts stand out about the fertility of American women. First, it has dropped drastically over the last two hundred years. This decline is called the demographic transition, but will be labeled here the baby bust. Second, the secular decline in fertility has had only one interruption, the baby boom. These two facts can easily be accounted for within the context of the neoclassical growth model. Just two modifications to the standard model are required: a fertility decision needs to be added, and household production incorporated.

\subsection{The environment}

Imagine a small open economy populated by overlapping generations. ${ }^{5}$ People live for three periods, one period as children and two as adults. Young adults are endowed with one unit of time. They can use this time for either working or raising kids. An individual is fecund only in the first period of adulthood. Old agents are retired.

Tastes. The lifetime utility function for a young adult is given by

$$
\phi \ln \left(c^{\mathrm{y}}+\mathfrak{c}\right)+\beta \phi \ln \left(c^{\mathrm{o} \prime}\right)+(1+\beta)(1-\phi) \ln n^{\mathrm{y}},
$$

where $c^{\mathrm{y}}$ and $c^{\mathrm{O} /}$ denote the adult's consumption when young and old, and $n^{\mathrm{y}}$ represents the number of kids that he would like to have when young. The constant $\mathfrak{c}$ proxies for the household production of market goods. As will be seen, it plays an important role in the analysis.

Income. Young agents work for the market wage $w$. They save for old age at the internationally determined time-invariant gross interest rate $r$.

Cost of children. Children are expensive. The production function for children is given by

$$
n^{\mathrm{y}}=x\left(l^{\mathrm{y}}\right)^{1-\gamma}
$$

where $l^{\mathrm{y}}$ is the time a young adult devotes to raising children and $x$ is the level of productivity in the home sector. The consumption cost, $k$, of raising $n^{\mathrm{y}}$ kids is therefore given by

$$
k=w\left(\frac{n^{\mathrm{y}}}{x}\right)^{1 /(1-\gamma)} .
$$

The cost of raising children is directly proportional to the wage rate.

5 The model presented here is based on Greenwood, Seshadri and Vandenbroucke (2005). 
The young agent's choice problem. The decision problem facing a young adult is

$$
\max _{c^{\mathrm{y}}, c^{\mathrm{o}^{\prime}}, n^{\mathrm{y}}}\left\{\phi \ln \left(c^{\mathrm{y}}+\mathfrak{c}\right)+\beta \phi \ln \left(c^{\mathrm{o} \prime}\right)+(1+\beta)(1-\phi) \ln n^{\mathrm{y}}\right\}
$$

subject to

$$
c^{\mathrm{y}}+\frac{c^{\mathrm{o} \prime}}{r}=w-w\left(\frac{n^{\mathrm{y}}}{x}\right)^{1 /(1-\gamma)} .
$$

The Euler equation for consumption is

$$
\frac{1}{c^{\mathrm{y}}+\mathrm{c}}=\beta r \frac{1}{c^{\mathrm{o} \prime}}
$$

which can be rewritten as

$$
c^{\mathrm{o}^{\prime}}=\beta r\left(c^{\mathrm{y}}+\mathfrak{c}\right) .
$$

This equation simply states that consumption of market goods over the household's lifetime will grow at the (gross) rate $\beta r$. If the gross rate of interest, $r$, exceeds the gross rate of time preference, $1 / \beta$, consumption increases over the household's lifetime, and likewise will decline when $r<1 / \beta$.

The above optimization problem can be reformulated using (3) to appear as

$$
\max _{c^{\mathrm{y}}, n^{\mathrm{y}}}\left\{(1+\beta)\left[\phi \ln \left(c^{\mathrm{y}}+\mathfrak{c}\right)+(1-\phi) \ln n^{\mathrm{y}}\right]+\beta \phi \ln (\beta r)\right\}
$$

subject to

$$
c^{\mathrm{y}}+\mathfrak{c}=\frac{1}{1+\beta}\left[w-w\left(\frac{n^{\mathrm{y}}}{x}\right)^{1 /(1-\gamma)}+\mathfrak{c}\right] .
$$

The first-order condition to this problem is

$$
\frac{\phi}{c^{\mathrm{y}}+\mathfrak{c}} \frac{1}{1+\beta} \frac{1}{1-\gamma} w x^{-1 /(1-\gamma)}\left(n^{\mathrm{y}}\right)^{\gamma /(1-\gamma)}=\frac{1-\phi}{n^{\mathrm{y}}} .
$$

The right-hand side of this equation gives the marginal benefit from having an extra kid. The left-hand side represents the marginal cost. This is the product of two components. Having an extra child necessitates working less in the market. This will lead to a sacrifice in terms of market consumption in the amount $[(1+\beta) \times$ $(1-\gamma)]^{-1} w x^{-1 /(1-\gamma)}\left(n^{\mathrm{y}}\right)^{\gamma /(1-\gamma)}$. The marginal utility derived from an extra unit of consumption is $\phi /\left(c^{\mathrm{y}}+\mathfrak{c}\right)$.

The firm's problem. Let market output, $o$, be produced in line with the following production function:

$$
o=z k^{\alpha} l^{1-\alpha},
$$

where $k$ and $l$ are the inputs of capital and labor used in production and $z$ is the level of productivity in the market sector. Now, suppose that capital depreciates fully after 
use in production. The rental rate on capital will then be $r$, since it must yield the same return as a bond. The problem facing the firm is therefore given by

$$
\max _{k, l}\left\{z k^{\alpha} l^{1-\alpha}-r k-w l\right\} \text {. }
$$

The first-order conditions connected to this problem are

$$
\alpha z k^{\alpha-1} l^{1-\alpha}=r
$$

and

$$
(1-\alpha) z k^{\alpha} l^{-\alpha}=w .
$$

These first-order conditions simply state that each factor gets paid its marginal product.

By substituting Equation (7) into (8), it is easy to see that

$$
w=(1-\alpha) \alpha^{\alpha /(1-\alpha)} z^{1 /(1-\alpha)} r^{-\alpha /(1-\alpha)} \text {. }
$$

Hence, the wage rate, $w$, is determined by the level of market productivity $z$ and the international rate of return on capital $r$.

Population growth. Let $s^{\mathrm{y}}$ and $s^{\mathrm{o}}$ stand for the current sizes of the young and old adult populations, respectively. Since today's young generation will be tomorrow's old generation it must transpire that

$$
s^{\mathrm{o} \prime}=s^{\mathrm{y}},
$$

where a prime affixed to a variable denotes its value next period. Now, each young adult has $n^{\mathrm{y}}$ kids so the size of next period's young generation is given by

$$
s^{\mathrm{y} \prime}=n^{\mathrm{y}} s^{\mathrm{y}} .
$$

\subsection{Analysis}

LEMMA 1. Fertility, $n^{\mathrm{y}}$, decreases with market wages $w$ and increases with the state of technology in the home sector, $x$.

PROOF. Take the first-order condition for $n^{\mathrm{y}}$, or (6), and rewrite it as

$$
n^{\mathrm{y}}=A^{1-\gamma} x\left[\frac{c^{\mathrm{y}}+\mathfrak{c}}{w}\right]^{1-\gamma},
$$

where

$$
A \equiv \frac{(1+\beta)(1-\gamma)(1-\phi)}{\phi} .
$$

Plugging the above equation into the budget constraint (5) yields

$$
c^{\mathrm{y}}+\mathfrak{c}=\frac{1}{1+\beta+A}(w+\mathfrak{c}) .
$$


Last, using the solution for $c^{\mathrm{y}}+\mathfrak{c}$ in (12) generates

$$
n^{\mathrm{y}}=\left[\frac{A}{1+\beta+A}\right]^{1-\gamma} x\left(1+\frac{\mathfrak{c}}{w}\right)^{1-\gamma} .
$$

The proof is now complete since it is trivial to see that $n^{\mathrm{y}}$ is decreasing in $w$ and increasing in $x$.

Intuition. With the aid of some diagrams, it is easy to ferret out the intuition underlying the above lemma. First, observe that (5) specifies the consumption possibilities frontier facing the household. The slope of the frontier is

$$
\frac{\mathrm{d}\left(c^{\mathrm{y}}+\mathfrak{c}\right)}{\mathrm{d} n^{\mathrm{y}}}=-w\left(\frac{1}{x}\right)^{1 /(1-\gamma)} \frac{\left(n^{\mathrm{y}}\right)^{\gamma /(1-\gamma)}}{(1+\beta)(1-\gamma)} \leqslant 0 .
$$

This is shown in Figure 4 by the concave consumption possibilities frontier, labeled PP. The frontier hits the vertical axis at the point $c^{\mathrm{y}}+\mathfrak{c}=[w+\mathfrak{c}] /(1+\beta)$, and the horizontal one at $n^{\mathrm{y}}=x(1+\mathfrak{c} / w)^{1-\gamma}$.

The objective function (4) defines indifference curves over the various $\left(n^{\mathrm{y}}, c^{\mathrm{y}}+\mathfrak{c}\right)$ combinations. The slope of an indifference curve is given by

$$
\left.\frac{\mathrm{d}\left(c^{\mathrm{y}}+\mathfrak{c}\right)}{\mathrm{d} n^{\mathrm{y}}}\right|_{\text {utility constant }}=-\frac{(1-\phi)}{\phi} \frac{c^{\mathrm{y}}+\mathfrak{c}}{n^{\mathrm{y}}} \leqslant 0 .
$$

The equilibrium level of fertility and market consumption are shown in standard fashion by the point $\left(n^{\mathrm{y} *}, c^{\mathrm{y} *}+\mathfrak{c}\right)$ where the indifference curve is tangent to the consumption possibilities frontier - see Figure 4.

Let wages increase by a factor of $\lambda$ and assume that $\mathfrak{c}=0$. In response, the consumption possibilities frontier will rotate upwards from the curve PP, by a factor of $\lambda$, to the

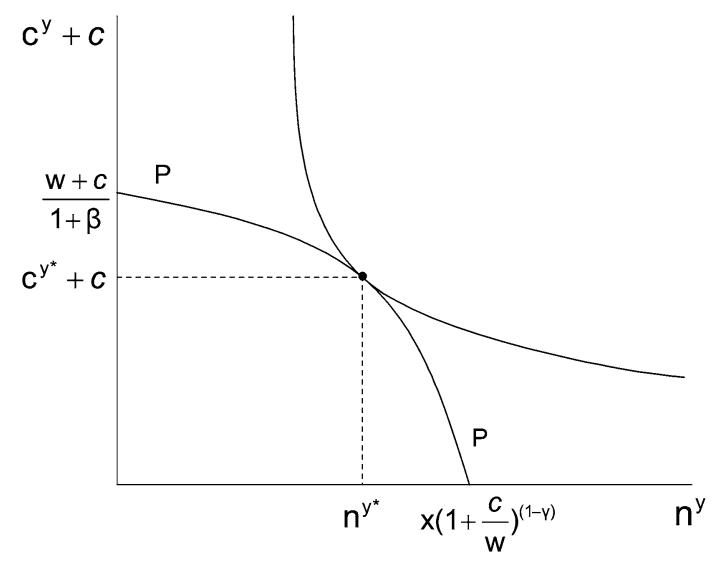

Figure 4. The determination of fertility. 


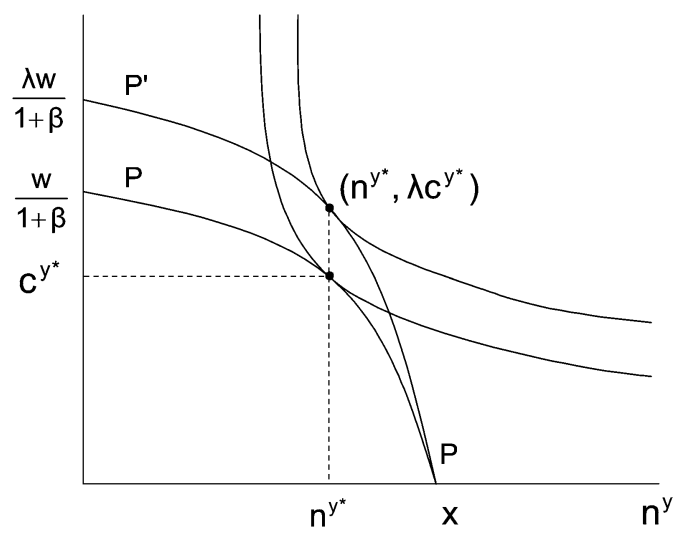

Figure 5. The effect of an increase in wages on fertility when $\mathfrak{c}=0$.

position shown by the curve $\mathrm{P}^{\prime} \mathrm{P}-$ see Figure 5 . Thus, there is a positive income effect associated with an increase in wages. The slope of the consumption possibilities curve will increase by a factor of $\lambda$ at any $n^{\mathrm{y}}$ point, too, as is evident from (14). That is, the marginal cost of an extra child rises. This effect should operate to reduce fertility. It is easy to deduce that consumption, $c^{\mathrm{y}}$, will move up by a factor of $\lambda$ and that fertility, $n^{\mathrm{y}}$, will remain constant. This transpires because the substitution and income effects on fertility from an increase in wages exactly cancel out, an artifice of the logarithmic form of preferences adopted in (1). To see this, note that along any vertical line the slopes of the indifference curves increase in proportion with the increases in $c^{\mathrm{y}}$, as is clear from (15). The slope of the indifference curve at the point $\left(n^{\mathrm{y} *}, \lambda c^{\mathrm{y} *}\right)$ is higher by a factor of exactly $\lambda$ relative to the slope of the curve at the point $\left(n^{\mathrm{y} *}, c^{\mathrm{y} *}\right)$.

Now suppose that wages jump up by a factor of $\lambda$ and assume that $\mathfrak{c}>0$. The consumption possibilities frontier no longer shifts upwards in a proportional manner. The horizontal intercept now shifts in - see Figure 6. A higher wage rate implies that the household production of market goods, $\mathfrak{c}$, now frees up less time for kids. As can be seen, fertility must unambiguously fall from $n^{\mathrm{y} *}$ to $n^{\mathrm{y} * \prime}$. Why? Suppose that fertility remains fixed at its old level $n^{\mathrm{y} *}$ and that consumption once again rises by a factor of $\lambda$, say from $c^{\mathrm{y} *}$ to $\lambda c^{\mathrm{y} *}$. (Note that $c^{\mathrm{y} *}$ and $\lambda c^{\mathrm{y} *}$ are not labeled on the diagram.) The slope of the consumption possibilities frontier will once again increase by a factor of $\lambda$, in line with (14). The slope of the indifference curve through the point $\left(n^{\mathrm{y}}, \lambda c^{\mathrm{y}}+\mathfrak{c}\right)$ will increase by less, though, due to the presence of the $\mathfrak{c}$ term in preferences - see (15) and the dashed indifference curve in Figure 6. Hence, a point of tangency cannot occur. At the margin a parent is willing to give up a child for $[(1-\phi) / \phi]\left(\lambda c^{\mathrm{y} *}+\mathfrak{c}\right) / n^{\mathrm{y} *}$ units of consumption. According to his production possibilities he can get $\lambda w(1 / x)^{1 /(1-\gamma)}\left(n^{\mathrm{y} *}\right)^{\gamma /(1-\gamma)} /[(1+\beta)(1-\gamma)]$ units of consumption for an incremental cut in fertility. Now, $[(1-\phi) / \phi]\left(\lambda c^{\mathrm{y} *}+\mathfrak{c}\right) / n^{\mathrm{y} *}<$ $\lambda w(1 / x)^{1 /(1-\gamma)}\left(n^{\mathrm{y} *}\right)^{\gamma /(1-\gamma)} /[(1+\beta)(1-\gamma)]$, since $[(1-\phi) / \phi]\left(c^{\mathrm{y} *}+\mathfrak{c}\right) / n^{\mathrm{y} *}=$ 


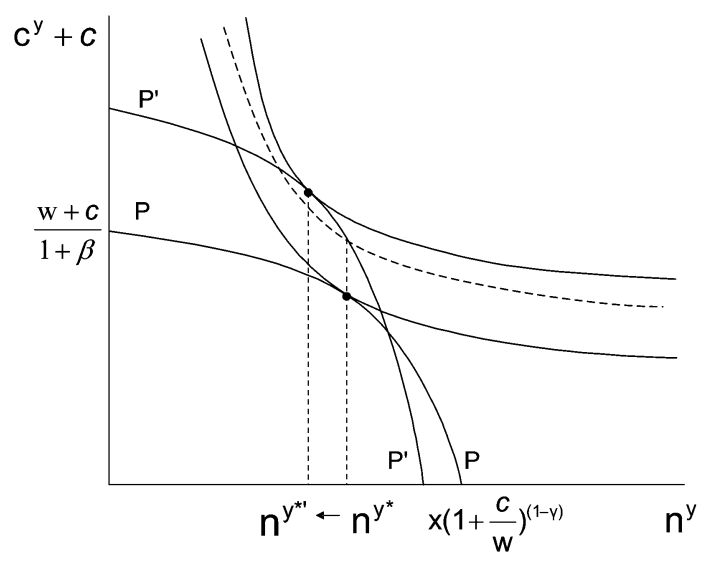

Figure 6. The effect of wages on fertility when $\mathfrak{c} \neq 0$.

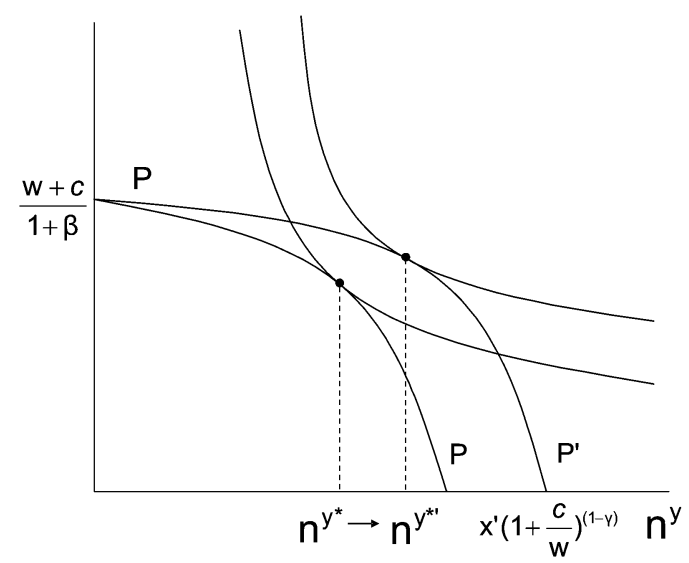

Figure 7. The effect of an improvement in household technology on fertility.

$w(1 / x)^{1 /(1-\gamma)}\left(n^{\mathrm{y} *}\right)^{\gamma /(1-\gamma)} /[(1+\beta)(1-\gamma)]$. Therefore, he should cut his level of fertility. In other words, when $\mathfrak{c}>0$ the substitution effect from an increase in $w$ outweighs the income effect.

Last, consider the effect of technological progress in the household sector. An increase in $x$ shifts the consumption possibilities frontier outwards in the manner shown by Figure 7 (from PP to $\mathrm{PP}^{\prime}$ ). At any $n^{\mathrm{y}}$ point the consumption possibilities curve becomes less steep since the consumption cost of an extra kid falls. As a result, both the income and substitution effects operate to increase fertility. (Since kids are a normal good, as one moves upwards along any vertical line the slopes of the indifference curves increase. This implies that the new consumption point must lie to right of $n^{\mathrm{y}}$.) 
COROLlary. Fertility, $n^{\mathrm{y}}$, is decreasing in the level of market productivity $z$. (Fertility is increasing in the international rate of return $r$.)

Proof. Substitute Equation (9) into (13) to get

$$
n^{\mathrm{y}}=\left[\frac{A}{1+\beta+A}\right]^{1-\gamma} x\left[\frac{1+\mathfrak{c} \alpha^{-\alpha /(1-\alpha)} z^{-1 /(1-\alpha)} r^{\alpha /(1-\alpha)}}{1-\alpha}\right]^{1-\gamma} .
$$

The desired result is now immediate. ${ }^{6}$

The baby bust. Now, suppose that market productivity is advancing over time at the constant rate $z^{\prime} / z=\zeta>1$. Wages must be growing at the constant rate $\zeta^{1 /(1-\alpha)}>1$, a fact evident from (9). Assume that there is no technological progress in the home sector. Fertility declines monotonically over time, as is immediate from (13). Since $w$ is growing at a constant rate it must transpire that $\mathfrak{c} / w \rightarrow 0$ over time. Therefore, fertility converges from above to

$$
n^{\mathrm{y}}=\left[\frac{A}{1+\beta+A}\right]^{1-\gamma} x .
$$

Observe that

$$
n^{\mathrm{y}} \gtreqless 1 \quad \text { as } \quad x \gtreqless\left[\frac{1+\beta+A}{A}\right]^{1-\gamma} .
$$

Using (10) and (11) it is easy to see that the long-run growth rate of the population can be expressed as

$$
\frac{s^{\mathrm{y} \prime}+s^{\mathrm{o} \prime}}{s^{\mathrm{y}}+s^{\mathrm{o}}}=\frac{n^{\mathrm{y}} s^{\mathrm{y}}+s^{\mathrm{y}}}{s^{\mathrm{y}}+s^{\mathrm{y}} / n^{\mathrm{y}}}=\frac{n^{\mathrm{y}}+1}{1+1 / n^{\mathrm{y}}}=n^{\mathrm{y}} .
$$

Hence, in the long-run the population may grow or shrink depending on the value of $x$.

EXAMPLE 1 (Fertility, 1800 and 1940). Assign the following parameter values to the model.

(i) Tastes: $\beta=0.94^{20}, \phi=0.47, \mathfrak{c}=2.97$.

(ii) Technology: $\alpha=0.33, \gamma=0.33, r=1 / \beta$.

Normalize the level of market and home productivity for the year 1800 to be unity. That is, set $x=z=1.0$ for 1800 . With this configuration of parameter values, Equation (16) predicts that the level of fertility per adult should be 3.5 , exactly the value observed in the U.S. in 1800 - at that time a married couple experienced 7 births on average. Now, between 1800 and 1940 market productivity grew by a factor of 3.5. So, reset $z$ to equal 3.5 for 1940 . The model predicts that fertility should fall to 1.2. It actually fell to 1.1 .

6 The intuition is obvious since $w$, the wage rate, is increasing in $z$ and decreasing in $r$. 
The baby boom. Once again presume that market productivity is growing over time at the constant rate $z^{\prime} / z=\zeta>1$. Now imagine that a once-and-for-all jump in household productivity happens. According to (13), fertility will jump up on this account. After this innovation fertility will revert back to its old time path of monotonic decline.

EXAMPLE 2 (Fertility, 1960 and 2000). Keep the parameter values from the previous example. U.S. fertility per prime-age adult (males plus females) rose from 1.1 to 1.8 between 1940 and 1960. This was the baby boom. By 1960 market-sector TFP had risen to 4.9 , so now reset $z=4.9$ for 1960 . Using (16) it is easy to deduce that a fertility rate of 1.8 can be obtained by letting $x=1.8$. That is, the baby boom can be generated by assuming that household-sector productivity grew by a factor 1.8 between 1940 and 1960. Finally, U.S. TFP had risen to 7.4 by the year 2000 . The model predicts that the fertility rate should be 1.5 , as opposed to the observed rate of 1.0 .

\section{The U.S. demographic transition}

At the start of the nineteenth century most adult males worked in the agricultural sector and children got very little in the way of a formal education. By the end of the twentieth century almost no adult worked in agriculture, at least relative to nonagriculture. The average child received about 13 years of formal education. To address these facts, a twosector version of the standard neoclassical growth model will be employed. One sector will represent agriculture, the other manufacturing. Agriculture hires unskilled workers while manufacturing employs skilled ones. In the framework developed, parents will decide upon both the number of children to have and the level of education for their offspring. The idea is that as manufacturing expands relative to agriculture, the demand for skilled labor rises. This entices parents to provide more education for their children. Since education is costly, they choose to have less kids too.

\subsection{The environment}

Take the setup of the previous section with two slight modifications. ${ }^{7}$ First, assume that parents now care about the quality of their children in addition to the quantity of them. Second, suppose that there are two production sectors in the economy. One sector uses solely skilled labor, the other only unskilled workers. A unit of skilled labor earns the wage $v$, while a unit of unskilled labor gets $w$. A parent must choose the skill level to endow his offspring with (or the quality of his children).

\footnotetext{
7 The model presented below is a simplified version of Greenwood and Seshadri (2002). Some aspects of the framework also bear a resemblance to Hansen and Prescott (2002) and Fernandez-Villaverde (2001).
} 
Tastes. A young adult's preferences are described by

$$
\psi \ln \left(c^{\mathrm{y}}\right)+\beta \psi \ln \left(c^{\mathrm{o} \prime}\right)+(1+\beta) \chi \ln n^{\mathrm{y}}+(1+\beta) \chi \ln \left[w^{\prime}\left(1-h^{\prime}\right)+v^{\prime} h^{\prime}\right],
$$

with $0 \leqslant h^{\prime} \leqslant 1$. This utility function is identical to (1), with two modifications. First, the children's skill level, $h^{\prime}$, now enters into the utility function. Other things equal, a parent would prefer to have skilled children because they will earn a higher wage when they grow up than unskilled children; i.e., $v^{\prime}>w^{\prime}$. In particular, a child's labor earnings are a weighted average of next period's skilled and unskilled wage rates, $w^{\prime}(1-$ $\left.h^{\prime}\right)+v^{\prime} h^{\prime}$, where the weight on the skilled wage rate is the child's skill level. Second, the constant term $\mathfrak{c}$ in (1) is now deleted. This term is responsible for getting fertility to fall as wages rise in the previous model - see (13). The current setup will rely instead on a quantity-quality trade-off in raising children to generate the decline in fertility.

Output. Suppose that consumption goods can be made using one of two production functions, a primitive technology, say agriculture, that converts unskilled labor into output

$$
o^{\mathrm{u}}=\frac{x u^{\sigma}}{\sigma},
$$

and a modern technology, read manufacturing, that transforms skilled labor into output

$$
o^{\mathrm{s}}=\frac{z s^{\sigma}}{\sigma} .
$$

In the above expressions $o^{\mathrm{u}}$ and $o^{\mathrm{s}}$ are the levels of output produced by the primitive and modern technologies, and $s$ and $u$ are the inputs of skilled and unskilled labor. Both technologies exhibit decreasing returns to scale. For simplicity, assume that each young adult owns a firm that can operate both of these technologies - hence the number of firms in the economy is the same as the number of young adults.

Budget constraint. The budget constraint for a young adult is

$$
c^{\mathrm{y}}+\frac{c^{\mathrm{o}^{\prime}}}{r}=\left(1-\tau n^{\mathrm{y}}-\phi n^{\mathrm{y}} h^{\prime}\right)[(1-h) w+h v+\pi] .
$$

There are two types of costs associated with having children, connected with birth $\tau$ and education $\phi$. These costs of having kids are expressed as fractions of family income. The young adult's skill level is represented by $h$ (versus $h^{\prime}$ for his children). Since each young adult owns one of each type of production function he earns the profits, $\pi$, associated with operating them. Family income is $(1-h) w+h v+\pi$. The cost of having $n^{\mathrm{y}}$ children, plus providing each of them with the human capital level $h^{\prime}$, is $\left(\tau n^{\mathrm{y}}+\phi n^{\mathrm{y}} h^{\prime}\right)[(1-h) w+h v+\pi]$. 
The young adult's choice problem. The decision problem facing a young adult is

$$
\begin{gathered}
\max _{c^{\mathrm{y}}, c^{\mathrm{O}^{\prime}}, h^{\prime}, n^{\mathrm{y}}}\left\{\psi \ln \left(c^{\mathrm{y}}\right)+\beta \psi \ln \left(c^{\mathrm{o} \prime}\right)+(1+\beta) \chi \ln n^{\mathrm{y}}\right. \\
\left.+(1+\beta) \chi \ln \left[w^{\prime}\left(1-h^{\prime}\right)+v^{\prime} h^{\prime}\right]\right\}
\end{gathered}
$$

subject to (18). The Euler equation for consumption is given by

$$
c^{\mathrm{o} \prime}=r \beta c^{\mathrm{y}}
$$

which has the same intuition as (3). This allows the above problem to be restated as

$$
\max _{c^{\mathrm{y}}, h^{\prime}, n^{\mathrm{y}}}\left\{\psi \ln \left(c^{\mathrm{y}}\right)+\chi \ln n^{\mathrm{y}}+\chi \ln \left[w^{\prime}\left(1-h^{\prime}\right)+v^{\prime} h^{\prime}\right]\right\}
$$

subject to

$$
c^{\mathrm{y}}=\left(1-\tau n^{\mathrm{y}}-\phi n^{\mathrm{y}} h^{\prime}\right) \frac{(1-h) w+h v+\pi}{1+\beta} .
$$

The first-order conditions with respect to $n^{\mathrm{y}}$ and $h^{\prime}$ (after solving out for $c^{\mathrm{y}}$ ) are

$$
\frac{\psi\left(\tau+\phi h^{\prime}\right)}{\left(1-\tau n^{\mathrm{y}}-\phi n^{\mathrm{y}} h^{\prime}\right)}=\frac{\chi}{n^{\mathrm{y}}}
$$

and

$$
\frac{\psi \phi n^{\mathrm{y}}}{\left(1-\tau n^{\mathrm{y}}-\phi n^{\mathrm{y}} h^{\prime}\right)}=\frac{\chi\left(v^{\prime}-w^{\prime}\right)}{w^{\prime}\left(1-h^{\prime}\right)+v^{\prime} h^{\prime}} .
$$

Dividing Equation (21) by Equation (22) yields

$$
\frac{\tau+\phi h^{\prime}}{\phi}=\frac{w^{\prime}\left(1-h^{\prime}\right)+v^{\prime} h^{\prime}}{v^{\prime}-w^{\prime}},
$$

which implies that

$$
\frac{w^{\prime}}{v^{\prime}}=\frac{\tau}{\tau+\phi} .
$$

In other words, tomorrow's skill premium is a constant, pinned down by the proportional costs for birth and education. Note that this follows directly from the assumption that quantity and quality have same weight $\chi$ in the utility function.

The firms' problems. The firms in the agricultural and manufacturing sectors will solve the problems

$$
\pi^{\mathrm{u}} \equiv \max _{\mathrm{u}}\left\{\frac{x u^{\sigma}}{\sigma}-w u\right\}
$$

and

$$
\pi^{\mathrm{s}} \equiv \max _{\mathrm{s}}\left\{\frac{z s^{\sigma}}{\sigma}-v s\right\} .
$$


The first-order conditions associated with these problems are

$$
w=x u^{\sigma-1}
$$

and

$$
v=z s^{\sigma-1} .
$$

The profits earned by a young agent from operating these firms will be $\pi=\pi^{\mathrm{u}}+\pi^{\mathrm{s}}$.

Population growth. Let $s^{\mathrm{y}}$ and $s^{\mathrm{o}}$ stand for the current sizes of the young and old adult populations, respectively. The manner in which these populations evolve is exactly the same as that in Section 2 and is given by Equations (10) and (11) - from here on out $n^{\mathrm{y}}$ will be replaced by $n$.

Labor market clearing conditions. The markets for unskilled labor and skilled labor must clear each period. Consequently, the equations

$$
u=(1-h)
$$

and

$$
s=h
$$

hold. (Recall that each young adult owns, and supplies labor, to his own firms.)

Equilibrium. Using these two market clearing conditions in the firms' first-order conditions (24) and (25) yields

$$
w=x[(1-h)]^{\sigma-1}
$$

and

$$
v=z(h)^{\sigma-1} \text {. }
$$

Substituting Equations (27) and (28) into (23) gives a single equation determining the human capital for a child, $h^{\prime}$,

$$
x^{\prime}\left(1-h^{\prime}\right)^{\sigma-1}=\left(\frac{\tau}{\tau+\phi}\right) z^{\prime} h^{\prime \sigma-1} .
$$

The right-hand side implicitly represents the demand for skilled labor in the manufacturing sector. ${ }^{8}$ The left-hand side specifies the supply of skilled labor available by

8 It comes from (28), which implies that

$$
h^{\prime}=\left(z^{\prime} / v^{\prime}\right)^{1 /(1-\sigma)} .
$$

As can be seen, the demand for skilled labor, $h^{\prime}$, is decreasing in the skilled wage $v^{\prime}$. 
freeing up workers from agriculture. ${ }^{9}$ This equation can be solved to get a closed-form expression for the level of human capital that reads

$$
h^{\prime}=\frac{1}{1+\omega\left(z^{\prime} / x^{\prime}\right)^{1 /(\sigma-1)}},
$$

where $\omega \equiv[\tau /(\tau+\phi)]^{1 /(\sigma-1)}>1$.

\subsection{Analysis}

Now, imagine that the economy is resting in a steady state where $z^{\prime}$ and $x^{\prime}$ are constant. It is then easy to see from (30) that $h^{\prime}$ will be constant. Notice that if $z^{\prime}$ and $x^{\prime}$ were to increase at the same rate, $h^{\prime}$ would also remain unchanged. This result follows because identical increases in total factor productivity in both sectors leave unchanged the demand for each type of labor, given the constancy of the skill premium. This leaves unchanged the fraction of total labor allocated to each sector. So, when will human capital rise?

LEMMA 2. As TFP in manufacturing, $z$, rises relative to agriculture $x$, human capital, $h$, increases and fertility, $n$, falls.

PROOF. Using a backdated version of (30), it is easy to calculate that the derivative of $h$ with respect to $z / x$ is given by

$$
\frac{\partial h}{\partial(z / x)}=\frac{1}{\left[1+\omega(z / x)^{1 /(\sigma-1)}\right]^{2}} \frac{\omega}{1-\sigma}(z / x)^{1 /(\sigma-1)-1}>0,
$$

since $\sigma<1$. Now, using (30), Equation (21) may be rewritten as

$$
\begin{aligned}
n & =\frac{\chi}{(\psi+\chi)\left[\tau+\phi /\left(1+\omega(z / x)^{1 /(\sigma-1)}\right)\right]} \\
& =\frac{\chi}{\psi+\chi} \frac{1+\omega(z / x)^{1 /(\sigma-1)}}{\left[\tau+\phi+\tau \omega(z / x)^{1 /(\sigma-1)}\right]} .
\end{aligned}
$$

Hence,

$$
\frac{\partial n}{\partial(z / x)}=-\frac{\chi}{\psi+\chi} \frac{1}{\left[\tau+\phi+\tau \omega(z / x)^{1 /(\sigma-1)}\right]^{2}} \frac{\phi \omega}{1-\sigma}(z / x)^{1 /(\sigma-1)-1}<0 .
$$

9 The left-hand side is based on (27). Equation (27) can be rewritten as

$$
h^{\prime}=1-\left(x^{\prime} / w^{\prime}\right)^{1 /(1-\sigma)} .
$$

Hence, $h^{\prime}$ is increasing in the unskilled wage, or equivalently the skilled wage using (23). 
The above lemma suggests that faster technological progress in the manufacturing sector, relative to the agricultural sector, increases the demand for skilled labor and this triggers a demographic transition and a rise in educational attainment. This accords well with U.S. historical experience.

What happens in the very long run?

LEMMA 3. As $z / x \rightarrow \infty$, the agricultural sector vanishes or $h \rightarrow 1$ and fertility declines to its lower bound, $n^{*}=\chi /[(\psi+\chi)(\tau+\phi)]$.

Proof. From Equation (30), backdated, it is easy to see that $h \rightarrow 1$ as $z / x \rightarrow \infty$. Further, Equation (21) implies that $n \rightarrow n^{*}=\chi /[(\psi+\chi)(\tau+\phi)]$.

Asymptotically, agriculture's share of GDP goes to zero as everyone in the economy becomes skilled. The economy eventually converges to a steady state where population grows at the constant rate $n^{*}$. One objection might be that, in reality, the ratio of manufacturing TFP to agricultural TFP has only grown two-fold or so during the last 200 years, thereby calling into question the importance of the above lemma. This is certainly true. A more realistic setup would have agricultural and manufacturing goods entering the utility function separately, with agricultural goods having a lower income elasticity of demand. As incomes rise, identical increases in $z$ and $x$ will reduce the demand for agricultural goods relative to manufacturing goods, at least in a closed economy. This creates an additional channel for structural transformation. Now, what can be said about the dynamics of human capital and fertility as $z$ rises relative to $x$ ? Lemma 4 and its corollary provide a characterization.

LEMMA 4. Human capital $h$ is convex in $z / x$ when $z / x<[\omega \sigma /(2-\sigma)]^{1-\sigma}=(z / x)^{*}$, and is concave otherwise.

ProOF. Using Equation (31), it can be deduced that

$$
\begin{aligned}
\frac{\partial^{2} h}{\partial(z / x)^{2}}= & \frac{\omega}{1-\sigma} \frac{1}{\left[1+(z / x)^{1 /(\sigma-1)}\right]^{3}} \frac{1}{1-\sigma} \\
& \times(z / x)^{1 /(\sigma-1)-2}\left[\sigma+\omega \sigma(z / x)^{1 /(\sigma-1)}-2\right] .
\end{aligned}
$$

Now,

$$
\frac{\partial^{2} h}{\partial(z / x)^{2}} \gtreqless 0 \quad \text { as } \quad \sigma+\omega \sigma(z / x)^{1 /(\sigma-1)} \gtreqless 2,
$$

or as

$$
\frac{z}{x} \lesseqgtr\left(\frac{\omega \sigma}{2-\sigma}\right)^{1-\sigma} .
$$

The above lemma indicates that when incomes are low, human capital will increase at an increasing rate when $z / x$ rises. After a certain point, the rate of increase in human 
capital will slow down, and human capital will increase at a decreasing rate as $z / x$ rises. Thus, the convergence of $h$ from a society where every individual is unskilled $(h=0)$ to one in which every one is skilled $(h=1)$ will have an $S$ shape that is characteristic of the diffusion of many innovations. Now, recall that fertility is inversely related to human capital. Consequently, fertility will initially fall at a increasing rate, and then will eventually decline at an decreasing rate as it converges to $n^{*}$. The following corollary characterizes the dynamics of fertility.

COROLlaRY. Fertility $n$ is convex in $z / x$ when $z / x>(\tau \omega \sigma /((\tau+\phi)(2-\sigma)))^{1-\sigma}=$ $(z / x)^{* *}$ and is concave otherwise.

Proof. Using Equation (32), it is easy to see that

$$
\begin{aligned}
\frac{\partial^{2} n}{\partial(z / x)^{2}}= & \frac{\chi}{\psi+\chi} \frac{\phi \omega}{1-\sigma} \frac{1}{1-\sigma}(z / x)^{1 /(\sigma-1)-2} \frac{1}{\left[\tau+\phi+\tau \omega(z / x)^{1 /(\sigma-1)}\right]^{3}} \\
& \times\left\{(\tau+\phi)(2-\sigma)-\tau \omega \sigma(z / x)^{1 /(\sigma-1)}\right\} .
\end{aligned}
$$

Now,

$$
\frac{\partial^{2} n}{\partial(z / x)^{2}} \gtreqless 0 \quad \text { as } \quad \frac{(\tau+\phi)(2-\sigma)}{\tau \omega \sigma} \gtreqless(z / x)^{1 /(\sigma-1)},
$$

or as

$$
\frac{z}{x} \gtreqless\left(\frac{\tau \omega \sigma}{(\tau+\phi)(2-\sigma)}\right)^{1-\sigma} .
$$

Figure 8 illustrates the dynamics of the transition path. One interesting aspect of the figure, as is evident from the above lemma and corollary, is that the point of inflection associated with the dynamics of fertility occurs at a lower value of $z / x$ than does the corresponding number for human capital; i.e., $(z / x)^{* *}<(z / x)^{*}$. This implies that the decline in fertility begins to slow down before the increase in human capital does. This is in accord with the evidence in the United States. What creates this asymmetry between the fall in fertility and the rise in human capital? The answer is the skill premium. Note that when the skill premium is zero, which transpires when $\phi=0,(z / x)^{* *}=(z / x)^{*}$. The analysis thus implies that economies with a higher skill premium will experience a longer delay between the slowdowns in the decline in fertility and the rise in human capital.

A numerical example will help clarify the ability of the model to match the historical facts.

EXAMPLE 3 (The U.S. demographic transition). Assume the parameter values given below.

(i) Tastes: $\beta=0.94^{20}, \chi=0.5, \psi=1-0.5$. 


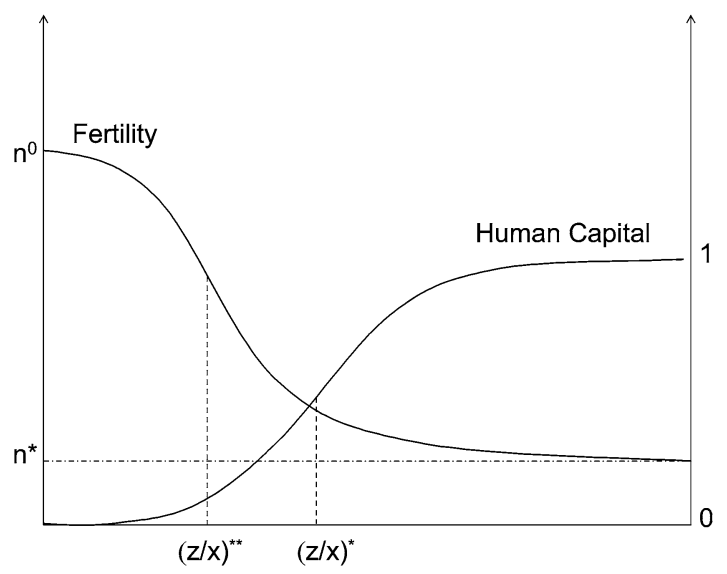

Figure 8. The dynamics of fertility and human capital.

(ii) Technology: $\sigma=0.8$.

(iii) Child care: $\tau=0.123, \phi=0.4$.

The time is 1800 . Assume that $(z / x)_{1800}=2.36$. Then, Equation (30) implies that $h_{1800}=0.05$; i.e., about 5 percent of the population are skilled. The rest of the population, 95 percent, live in the rural sector. Further, Equation (21) implies that $n_{1800}=\chi /\left[(\psi+\chi)\left(\tau+\phi h_{1800}\right)\right]=3.5$, which is exactly the number of kids per adult (male plus female) in 1800. An average married couple in 1800 had 7 kids. Now, move ahead to 1940 . TFP in agriculture grew by a factor of 1.95 , while TFP in manufacturing grew by a factor of 4.11. Consequently, $(z / x)_{1940}=(4.11 / 1.95) \times(z / x)_{1800}=4.97$. Now, Equation (30) implies that $h_{1940}=0.69$, or that about 31 percent of the population live in the rural sector. Further, $n_{1940}=\chi /\left[(\psi+\chi)\left(\tau+\phi h_{1940}\right)\right]=1.26$, so that an average family has 2.52 children (as opposed to 2.23 in the data). Finally, the long-run value of fertility is $n^{*}=0.96$. In the long run an average family will give birth to 1.92 children.

Notice that even without employing any differences in curvature between manufacturing or agricultural goods, or differences in the skill intensities associated with the production of these goods, technological advance can account for most of the decline in fertility between 1800 and $1940 .{ }^{10}$

10 Greenwood and Seshadri (2002) allow for agricultural and manufacturing goods to enter the utility function separately. The assumed form of their utility function ensures that agricultural goods have a lower income elasticity than do manufacturing goods. They show that a two-fold increase in $z / x$, together with a lower income elasticity of demand for agricultural goods relative to skill-intensive manufactured goods, can account for the demographic transition and the structural transformation that the United States experienced over the nineteenth and twentieth centuries. 


\section{The demise of child labor}

Economically valuable and emotionally worthless to economically worthless and emotionally valuable. In 1896 the Southern Railroad Company of Georgia was sued for the wrongful death of a two-year-old boy. ${ }^{11}$ The parents claimed that their son performed valuable services worth $\$ 2$ per month, "going upon errands to neighbors ... watching and amusing ... younger child". The court's judgement allowed just for minimum burial expenses to be recovered. The ruling stated that the youngster was "of such tender years as to be unable to have any earning capacity, and hence the defendant could not be held liable in damages". The problem was that the boy was too young to do productive work. And the court attached no value to the pain and suffering connected with the loss of a child. An older child could earn money, but it was still a fraction of what an adult would get. For example, a ten-year-old in 1798 could earn the equivalent of $\$ 22$ a year working as a farm laborer, as compared with $\$ 96$ for an adult - Lebergott (1964, pp. 49-50).

Now move forward in time to January 1979. The New York State Supreme Court jury awarded $\$ 750,000$ to the parents of three-year-old William Kennerly. He had been given a lethal dose of fluoride in a city dental clinic. The twentieth century has witnessed a profound transformation in the value of children. Along with the Second Industrial Revolution emerged the "economically worthless" and the "emotionally priceless" child. For in strict economic terms, today's children are worthless to their parents. They are expensive. The direct cost to a two-parent median income family of raising a child born in 1995 through to the age of 17 was estimated to be $\$ 145,320 .{ }^{12}$ And this does not include college costs, time costs, and foregone earnings. In return they provide no labor.

What caused this dramatic change in society's valuation of children over such a relatively short period of time? And what accounts for the apparent paradox that the value in the twentieth century that society placed on an economically useless child far surpassed the one in the nineteenth century that society placed on an economically useful child? A case can be made that technological progress resulted in the liberation of children from work. Increased mechanization of agriculture and manufacturing in the late nineteenth and early twentieth centuries resulted in a decline in the demand for unskilled labor and a rise in the demand for skilled labor. Thus, the return to skill rose. This created an incentive for parents both to educate their offspring more, and to have less of them; i.e., to substitute away from quantity toward quality of children. The death of child labor was natural.

11 This and the next case are taken from Zelizer (1994, pp. 138-139). This is the source for the quotations as well.

12 Source. Expenditures on Children by Families, 1995 Annual Report, USDA Miscellaneous Publication Number 1528-1995. 


\subsection{The environment}

The analysis here closely follows the setup of the previous section. Assume that an individual lives for three periods: the first as a child, and the second and third as an adult. In the first period of life a person undertakes no economic decisions; he simply accumulates the level of human capital dictated by his parents. He begins the second period of his life with a fixed number of children, $\eta$. In addition to being exogenous, childbearing is costless. Skilling a child, however, involves two costs. First, as before, there is the direct cost of educating the child. In particular, endowing a child with $h^{\prime}$ units of human capital involves a cost of $\phi h^{\prime}$ units of unskilled time. Second, there is the opportunity cost of sending the child to school; that is, by going to school a child forgoes some labor earnings. Specifically, suppose that a child is as productive in the labor market as $\zeta<1$ unskilled adults. Additionally, assume that in order for the child to acquire $h^{\prime}$ units of human capital he must go to school for $h^{\prime}$ units of time.

A young adult's decision problem. The economic environment is pretty much the same as that in the previous section, with the above notable exceptions. Another distinction is that a parent now cares about the leisure that his children will enjoy, in addition to his own consumption and the quality of his children. The purpose is to break the link between the time spent schooling and the time spent working by children. The analogue to choice problem (20) is

$$
\max _{c^{\mathrm{y}}, h^{\prime}, l}\left\{\psi \ln \left(c^{\mathrm{y}}\right)+\chi_{1} \ln \left[w^{\prime}\left(1-h^{\prime}\right)+v^{\prime} h^{\prime}\right]+\chi_{2} \ln l\right\}
$$

subject to

$$
c^{\mathrm{y}}=\frac{\left[(1-h) w+h v+\pi+w \zeta \eta\left(1-h^{\prime}-l\right)-w \phi \eta h^{\prime}\right]}{1+\beta},
$$

where once again consumption when old, $c^{0}$, has been substituted out using the Euler equation (19). In this maximization problem, $h$ denotes the human capital of the parent, $h^{\prime}$ the human capital of the child, $l$ the leisure time for the child, $w$ the unskilled wage rate, $v$ the skilled wage rate, and $\pi$ is the flow of profits associated with the operation of firms in the agricultural and manufacturing sectors.

The first-order condition for $h^{\prime}$ is

$$
\frac{\psi \eta}{1+\beta} \frac{w \zeta+w \phi}{c^{\mathrm{y}}}=\frac{\chi_{1}\left(v^{\prime}-w^{\prime}\right)}{w^{\prime}\left(1-h^{\prime}\right)+v^{\prime} h^{\prime}} .
$$

The right-hand side of this equation gives the value from extra human capital accumulation in children. It has the same form as (22). The left-hand side gives the cost of extra human capital accumulation. Observe that part of this cost is the forgone earnings $w \zeta$ that a child would realize by working instead of going to school. Also, the cost of educating kids is an increasing function of the number of kids $\eta$. Hence, one would expect that as $\eta$ falls $h^{\prime}$ should rise. Note that an equiproportionate increase in $v, v^{\prime}, w, w^{\prime}$ and $c^{\mathrm{y}}$ will have no effect on $h^{\prime}$. Consequently, along a balanced growth path $h$ will be 
constant. Hence, in order to get some action it must transpire that $v$ must rise relative to $w$, or equivalently that $z$ must increase relative to $x$. Recall that this was exactly what was needed to account for the U.S. demographic transition in Section 3.

Finally, the first-order condition for leisure reads

$$
\frac{\zeta \psi \eta}{1+\beta} \frac{w}{c^{\mathrm{y}}}=\frac{\chi_{2}}{l} \text {. }
$$

The right-hand side of this equation gives the marginal benefit from providing an extra unit of leisure to each child while the left-hand side gives the marginal cost. Observe that for leisure, $l$, to increase, $c^{\mathrm{y}}$ must rise relative to $w \eta$. This will happen if either $v$ rises relative to $w$, or if the level of human capital $h$ increases, ceteris paribus. Note that a fall in fertility, $\eta$, plays an important role in increasing $l$. When fertility declines, the marginal cost to the parent of providing more leisure to each of his children falls, hence leisure rises.

\subsection{Analysis}

Imagine that the economy is resting in a steady state where $z$ and $x$ are constant. ${ }^{13}$ Variables such as $h, l, w / c^{\mathrm{y}}$ and $v / c^{\mathrm{y}}$ will also be constant. Others such as the size of the young generation, $s^{\mathrm{y}}$, will be changing at a constant rate dictated by the size of $\eta$. The market-clearing condition for skilled labor will again be described by (26). The one for unskilled labor will now appear as

$$
u=[1-h+(1-h-l) \eta \zeta-\phi \eta h] .
$$

The firms' problems are exactly the same as in Section 3.1. In a steady-state situation, wages will be given by

$$
\begin{aligned}
& w=w^{\prime}=x[1-h+(1-h-l) \eta \zeta-\phi \eta h]^{\sigma-1}, \\
& v=v^{\prime}=z[h]^{\sigma-1},
\end{aligned}
$$

which follow from Equations (24), (25), (26) and (36).

In principle one can solve the first-order conditions (34) and (35), in conjunction with (37) and (38), to obtain a solution for $h$ and $l .{ }^{14}$ General results are hard to obtain for

13 For simplicity the analysis will be restricted to a study of comparative steady states.

14 Additionally, it is easy to show that profits are

$$
\pi=\left(\frac{1-\sigma}{\sigma}\right)\{w[1-h+(1-h-l) \eta \zeta-\phi \eta h]+v h\},
$$

so that consumption is given by

$$
\begin{aligned}
c^{\mathrm{y}} & =\frac{\{w[1-h+(1-h-l) \eta \zeta-\phi \eta h]+v h+\pi\}}{1+\beta} \\
& =\frac{1}{(1+\beta) \sigma}\{w[1-h+(1-h-l) \eta \zeta-\phi \eta h]+v h\} .
\end{aligned}
$$


this economy, however, so a numerical example will be used to highlight the effect of changes in $z / x$ and $\eta$ on $h .^{15}$ The goal of this example is to show that the above setup is capable of generating a large decline in child labor. Little attention has been paid to its realism.

EXAMPLE 4 (The natural death of child labor). Assume the parameter values listed below.

(i) Tastes: $\beta=0.94^{20}, \chi_{1}=0.14, \chi_{2}=0.03, \psi=1-\chi_{1}-\chi_{2}$.

(ii) Technology: $\sigma=0.7$.

(iii) Child care: $\phi=0.1$.

(iv) Child productivity: $\zeta=0.15$.

Again, start off in 1800 . Set $\eta_{1800}=3.5$, since an average family gave birth to 7 children. Observe that in work a child has the productivity of 0.15 adults. ${ }^{16}$ Assume that $z_{1800}=x_{1800}=1$. Then Equations (34) and (35) imply that $h_{1800}=0.025$ and $l_{1800}=0.16$; i.e., about $\left(1-h_{1800}-l_{1800}\right) \times 100=81.5$ percent of children are gainfully employed. Now, move ahead to 1940. TFP in agriculture grew by a factor of 1.95 while TFP in manufacturing grew by a factor of 4.11. Consequently, $(z / x)_{1940}=(4.11 / 1.95) \times(z / x)_{1800}=2.1$. Also, let $\eta_{1940}=1.1$. Now, $h_{1940}=0.49$ and $l_{1940}=0.51$ so that no child works in 1940 !

Child labor laws and compulsory schooling laws. Child labor laws are often cited as a reason for the decline in child labor. While the National Child Labor Committee was formed as early as 1904, it was not until 1938, when the Fair Labor Standards Act was passed, that children were freed from the bondage of dangerous work. The data suggests that the process of the withdrawal of children from the workforce had been completed before child labor laws were firmly in place. The conventional wisdom among economic historians is that these laws had little impact on teen attendance early in the twentieth century because the laws were imperfectly enforced [Landes and Solmon (1972) and Eisenberg (1988)]. More recent work by Margo and Finegan (1996) finds significant positive effects on school attendance when compulsory schooling laws were coupled with child labor laws. There is still the possibility that the enactment of these laws was a reaction to the greater demand for skilled labor, and the lower demand for unskilled labor, caused by industrialization. Nardinelli (1990) echoes this sentiment and provides evidence that those areas that industrialized first were also among the first to adopt these laws. Hence the enactment of these laws in more industrialized states is consistent with

15 Analytical solutions can be obtained in Section 3 due to the fact that the costs of raising kids are expressed as a fraction of family income. With child labor the convenience of this formulation disappears so a more traditional one is adopted - compare (18) with (33).

16 Recall that according to Lebergott (1964), a child in agriculture could earn $\$ 22$ in a year, while an adult would receive $8 \times 12=\$ 96$. Assuming that the child would work from the age of 7 , and given that a period in the model is 20 years, the child equivalent of a man is $(22 / 96) \times(13 / 20)=0.149$. 
the notion that technological progress increased the demand for skilled labor vis à vis unskilled labor and consequently reduced the demand for child labor.

The above example suggests that sector-specific technological progress alone can account for all of the decline in child labor. There are three effects at play. First, the demand for skilled labor rises relative to unskilled labor. This increases the skill premium, and promotes investment in skill via a substitution effect. Second, technological advance makes parents wealthier. This income effect makes parents more likely to invest in the well-being of their children. Third, fertility drops also, which reduces the cost of educating a family. Consequently, $h$ and $l$ both rise. A more serious treatment of the issue of child labor would endogenize fertility and incorporate the quantity-quality trade-off that parents face. There is one aspect of the data that make a technology-based explanation appealing. The period from 1900 to 1930 saw a dramatic decline in child labor. These three decades saw an enormous increase in manufacturing productivity relative to agricultural productivity $z / x$. The United States experience accords well with this implication. Last, observe that the utility flow that a parent realizes from a child increases with technological progress. This transpires because both the child's level of human capital (or quality) and leisure rise.

\section{Engines of liberation}

Is it, then, consistent to hold the developed woman of this day within the same narrow political limits as the dame with the spinning wheel and knitting needle occupied in the past? No, no! Machinery has taken the labors of woman as well as man on its tireless shoulders; the loom and the spinning wheel are but dreams of the past; the pen, the brush, the easel, the chisel, have taken their places, while the hopes and ambitions of women are essentially changed.

[Elizabeth Cady Stanton, "Solitude of Self", an address before United States Congressional Committee on the Judiciary, January 18, 1892.]

For ages woman was man's chattel, and in such condition progress for her was impossible; now she is emerging into real sex independence, and the resulting outlook is a dazzling one. This must be credited very largely to progression in mechanics; more especially to progression in electrical mechanics.

Under these new influences woman's brain will change and achieve new capabilities, both of effort and accomplishment.

[Thomas Alva Edison, as interviewed in Good Housekeeping Magazine, LV, no. 4 (October 1912, p. 440).]

The twentieth century witnessed a dramatic rise in labor-force participation by married women. ${ }^{17}$ It will be argued here that technological advance in the household sector

17 Labor-force participation also increased for single women, but not as dramatically. For instance, 38.4 percent of single white women worked in 1890 - Goldin (1990, Table 2.1, p. 17). By 1988 this had risen to 68.6 percent. 
liberated women from the home, in particular from the oppressive burden of housework. The standard Solow (1956)-Ramsey (1928) growth model will be extended along two dimensions. First, household production will be included in the framework. Second, a technology adoption decision will be incorporated into the analysis.

Time savings. As a backdrop to the subsequent analysis, a quick detour will be taken to consider some evidence on the reduction of time spent on housework. At the start of Second Industrial Revolution women's magazines were filled with articles extolling the virtues of appliances, the new domestic servants. For example, in 1920 an article in the Ladies' Home Journal entitled "Making Housekeeping Automatic" claimed that appliances could save a 4-person family 18.5 hours a week in housework - see Table 2. Some more scientific evidence comes from the sociology literature - see Table 3. In 1924 a pair of famous sociologists, Robert and Helen Lynd, studied a small town in Indiana, Middletown. They found that 87 percent of married women in 1924 spent 4 or more hours doing housework each day. Zero percent spent less than 1 hour a day. The town

Table 2

Estimated weekly hours saved by appliances

\begin{tabular}{lccc}
\hline Task & With appliances & Without appliances & Time savings \\
\hline Breakfast & 7 & 10 & 3 \\
Luncheons & 10.5 & 14 & 3.5 \\
Dinners & 10 & 12 & 2 \\
Dishwashing and clearing & 10.5 & 15.75 & 5.25 \\
Washing and ironing & 6.5 & 9 & 2.5 \\
Marketing and errands & 6 & 6 & 0 \\
Sewing and mending & 3.5 & 4 & 0.5 \\
Bed making & 2.75 & 3.5 & 0.75 \\
Cleaning and dusting & 2 & 3 & 1 \\
Cleaning kitchen and refrigerator & 2 & 2 & 0 \\
Total & 60.75 & 79.25 & 18.5 \\
\hline
\end{tabular}

Source: Ladies' Home Journal (1920).

Table 3

Daily housework in Middletown (percentage of married housewives in each category)

\begin{tabular}{cccc}
\hline Year & $\geqslant 4$ hours & $2-3$ hours & $\leqslant 1$ hour \\
\hline 1924 & 87 & 13 & 0 \\
1977 & 43 & 45 & 12 \\
1999 & 14 & 53 & 33 \\
\hline
\end{tabular}

Source: Caplow, Hicks and Wattenberg (2001, p. 37). 
was restudied by sociologists at two later dates. By 1999 only 14 percent of married women spent more than 4 hours a day on housework, and 33 percent spent less than 1 hour a day.

\subsection{The environment}

Consider a small open economy populated by overlapping generations. ${ }^{18}$ Individuals live for two periods, they work in the first period and retire in the second. They are endowed with one unit of time for either working in the market or at home.

Tastes. The lifetime utility function for a young adult is given by

$$
\mu \ln c^{\mathrm{y}}+(1-\mu) \ln n^{\mathrm{y}}+\beta \mu \ln c^{\mathrm{o} /}+\beta(1-\mu) \ln n^{\mathrm{o} \prime},
$$

where $c^{\mathrm{y}}$ and $c^{\mathrm{O} /}$ denote the individual's consumption when young and old, and (with a change in notation from the previous sections) $n^{\mathrm{y}}$ and $n^{\mathrm{o} /}$ now stand for young and old household production.

Income. Young adults work for the market wage, $w$. They save for old age at the internationally determined time-invariant gross interest rate $r$.

Household production technology. Let the production of home goods, $n$, be governed by

$$
n=\left[\theta \delta^{\kappa}+(1-\theta) h^{\kappa}\right]^{1 / \kappa} \quad \text { for } \kappa \leqslant 1,
$$

where $\delta$ is the stock of household capital and (with another change in notation) $h$ now represents the amount of time spent on housework. When $\kappa>0(\kappa<0)$, capital and labor are Edgeworth-Pareto substitutes (complements) in producing utility. ${ }^{19}$ Finally, assume that household capital is lumpy or indivisible. A person acquires this capital when young and keeps it for his entire life, whereupon it fully depreciates. Let the time cost of purchasing $\delta$ units of household capital be $q$.

18 The framework developed below is a stripped-down version of Greenwood, Seshadri and Yorukoglu (2005).

19 Let

$$
U(\delta, h) \equiv(1-\mu) \ln \left\{\left[\theta \delta^{\kappa}+(1-\theta) h^{\kappa}\right]^{1 / \kappa}\right\} .
$$

It is easy to see that

$$
U_{12}(\delta, h) \lesseqgtr 0 \quad \text { as } \kappa \gtreqless 0 .
$$


The young household's choice problem. Since the agent spends the entire one unit of his time endowment during retirement on household production, $h^{\mathrm{o} \prime}=1$. Consequently, $n^{\mathrm{o} \prime}=\left[\theta \delta^{\kappa}+(1-\theta)\right]^{1 / \kappa}$, a constant. The decision problem facing a young adult is

$$
\begin{aligned}
U(w, r, \delta, q)= & \max _{c^{\mathrm{y}}, h^{\mathrm{y}}, c^{\mathrm{o}^{\prime}}}\left\{\mu \ln c^{\mathrm{y}}+(1-\mu) \ln n^{\mathrm{y}}+\beta \mu \ln c^{\mathrm{o} \prime}\right\} \\
& +\beta(1-\mu) \ln \left[\theta \delta^{\kappa}+(1-\theta)\right]^{1 / \kappa}
\end{aligned}
$$

subject to

$$
c^{\mathrm{y}}+\frac{c^{\mathrm{o} \prime}}{r}=w\left(1-h^{\mathrm{y}}\right)-w q,
$$

and

$$
n^{\mathrm{y}}=\left[\theta \delta^{\kappa}+(1-\theta)\left(h^{\mathrm{y}}\right)^{\kappa}\right]^{1 / \kappa} .
$$

Since there is only one $h$ to worry about, let $h^{\mathrm{y}}=h$ from here on out to save on notation. The function $U$ is the household's indirect utility function. It gives the maximal level of utility that the household can attain given the prices $w, r$ and $q$, and the level of household capital $\delta$. Note the above problem presumes that the household purchases the household production technology represented by the pair $(\delta, q)$. This assumption will be relaxed later on.

The efficiency condition for housework reads

$$
\frac{\mu w}{c^{\mathrm{y}}}=\frac{1-\mu}{n^{\mathrm{y}}}\left[\theta \delta^{\kappa}+(1-\theta) h^{\kappa}\right]^{1 / \kappa-1}(1-\theta) h^{\kappa-1} .
$$

This above equation can be derived by using (41) and (42) to substitute out for $c^{\mathrm{y}}$ and $n^{\mathrm{y}}$ in (40) and then differentiating with respect to $h$. The left-hand side gives the marginal cost of an extra unit of housework. An extra unit of time spent in housework comes at the expense of a forgone unit of market work that earns the wage rate, $w$. To convert this into utility terms multiply by the marginal utility of consumption when young, $\mu / c^{\mathrm{y}}$. The right-hand side represents the marginal benefit from an extra unit of housework. An additional unit of time spent at home increases household production by the marginal product of labor, $\left[\theta \delta^{\kappa}+(1-\theta) h^{\kappa}\right]^{1 / \kappa-1}(1-\theta) h^{\kappa-1}$. To convert this to utility terms multiply by the marginal utility of home goods, $(1-\mu) / n^{\mathrm{y}}$. At the optimum, the marginal cost and benefit of housework must equal each other.

The Euler equation for consumption is exactly the same as Equation (19), which together with the budget constraint (41) gives

$$
c^{\mathrm{y}}=\frac{w[(1-h)-q]}{1+\beta} \quad \text { and } \quad c^{\mathrm{o} \prime}=\frac{\beta r w[(1-h)-q]}{1+\beta} .
$$

Now, using (42) and (44) to substitute out for $c^{\mathrm{y}}$ and $n^{\mathrm{y}}$ in (43), while rearranging, yields a single equation determining the equilibrium level of housework, $h$,

$$
1=\frac{1-\mu}{\mu(1+\beta)} \frac{(1-h)-q}{\left[\theta \delta^{\kappa}+(1-\theta) h^{\kappa}\right]}(1-\theta) h^{\kappa-1} .
$$

The intuition underlying this equation will be presented later on. 
The firm's problem. Once again let market output, $o$, be produced in line with the following production function:

$$
o=z k^{\alpha} l^{1-\alpha},
$$

where $k$ and $l$ are the inputs of capital and labor used in production and $z$ is the level of productivity in the market sector. Now, suppose that capital depreciates fully after use in production. The rental rate on capital will therefore be $r$, since it must yield the same return as a bond. Given this production structure, once again wages will be given by (9).

\subsection{Analysis}

What is the effect of technological advance in the home sector on the amount of time devoted to housework? The answer will depend upon whether capital and labor in household production are Edgeworth-Pareto substitutes or complements in generating utility. Likewise, what impact will technological progress in the market sector have on the amount of time allocated to housework?

LEMMA 5. An increase in the market wage rate, $w$, will have no effect on the amount of time spent in housework, $h$, while an increase in the stock of household capital, $\delta$, will

(a) cause $h$ to decline when capital and labor are Edgeworth-Pareto substitutes (or when $\kappa>0$ ),

(b) cause $h$ to increase when capital and labor are Edgeworth-Pareto complements (or when $\kappa<0$ ),

(c) have no effect on $h$ when capital and labor are neither Edgeworth-Pareto substitutes or complements (or when $\kappa=0$ ).

PROOF. The first part of the lemma is trivial since $w$ does not enter Equation (45) and therefore cannot influence $h$. To establish the second part of the lemma, totally differentiate (45) with respect to $h$ and $\delta$ to get

$$
\frac{\mathrm{d} h}{\mathrm{~d} \delta}=-\kappa \frac{[(1-h)-q] h \theta \delta^{\kappa-1}}{\left\{(1-q)\left[\theta \delta^{\kappa}+(1-\theta) h^{\kappa}\right]-\kappa(1-h-q) \theta \delta^{\kappa}\right\}} .
$$

Now, the denominator of the above expression is unambiguously positive since $\kappa \leqslant 1$ and $(1-q) \geqslant(1-h-q)$. Therefore,

$$
\operatorname{sign}\left(\frac{\mathrm{d} h}{\mathrm{~d} \delta}\right)=-\operatorname{sign}(\kappa) .
$$

COROLlARY. Technological progress in the market sector, or an increase in $z$, has no effect on time spent in housework $h$.

PROOF. The proof is trivial since $z$ does not enter (45), because $w$ does not. 


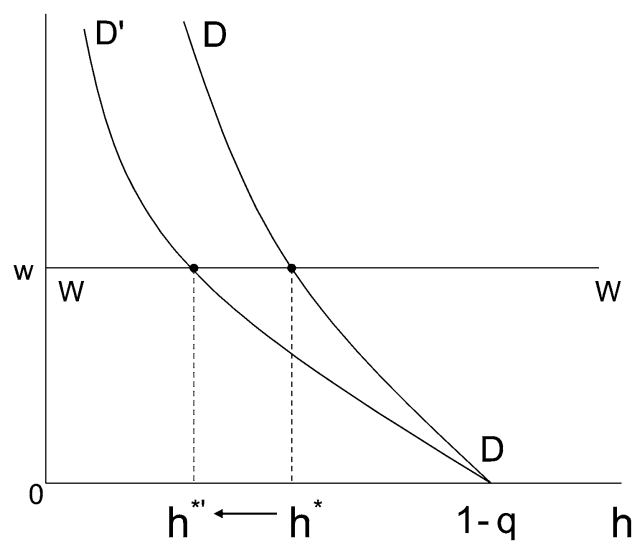

Figure 9. The effect of an improvement in household technology on time spent on housework.

Intuition. Observe that the first-order condition (43) can be expressed as

$$
w=\frac{1-\mu}{\mu} \frac{c^{\mathrm{y}}}{n^{\mathrm{y}}}\left[\theta \delta^{\kappa}+(1-\theta) h^{\kappa}\right]^{1 / \kappa-1}(1-\theta) h^{\kappa-1} .
$$

The left-hand side of this above equation is the marginal product of labor in the market sector, $w$. This is portrayed by the WW curve in Figure 9. The value of the marginal product of labor in the home sector is given by the right-hand side. This equals the marginal product of labor in the home sector, $\left[\theta \delta^{\kappa}+(1-\theta) h^{\kappa}\right]^{1 / \kappa-1}(1-\theta) h^{\kappa-1}$, multiplied by the (implicit) relative price of home goods, $[(1-\mu) / \mu] c^{\mathrm{y}} / n^{\mathrm{y}}$. Substituting out for $c^{\mathrm{y}}$ and $n^{\mathrm{y}}$, using (44) and (42), gives

$$
\begin{aligned}
w & =\frac{1-\mu}{\mu(1+\beta)} \frac{w[(1-h)-q]}{\left[\theta \delta^{\kappa}+(1-\theta) h^{\kappa}\right]^{1 / \kappa}}\left[\theta \delta^{\kappa}+(1-\theta) h^{\kappa}\right]^{1 / \kappa-1}(1-\theta) h^{\kappa-1} \\
& =\frac{1-\mu}{\mu(1+\beta)} \frac{w[(1-h)-q]}{\left[\theta \delta^{\kappa}+(1-\theta) h^{\kappa}\right]}(1-\theta) h^{\kappa-1} \\
& \equiv \operatorname{RHS}(h ; \delta, w) .
\end{aligned}
$$

The right-hand side of the equation spells out the demand curve for housework, $h$. It is shown in Figure 9 by the DD curve. This curve is decreasing in $h$, a fact easily deduced by observing that both the price and marginal product terms are decreasing in $h$. Note that $\operatorname{RHS}(h ; \delta, w) \rightarrow \infty$ as $h \rightarrow 0$, and that $\operatorname{RHS}(h ; \delta, w) \rightarrow 0$ as $h \rightarrow 1-q$.

The equilibrium level of housework, $h^{*}$, is given by the point where the DD and WW curves intersect. So, how will technological advance in the home sector affect the equilibrium level of housework? It is clear from (46) that

$$
\begin{aligned}
\frac{\partial \operatorname{RHS}(h ; \delta, w)}{\partial \delta}= & -\kappa \frac{1-\mu}{\mu(1+\beta)} \frac{w[(1-h)-q]}{\left[\theta \delta^{\kappa}+(1-\theta) h^{\kappa}\right]^{2}} \\
& \times(1-\theta) h^{\kappa-1} \theta \delta^{\kappa-1} \lesseqgtr 0 \quad \text { as } \kappa \gtreqless 0 .
\end{aligned}
$$




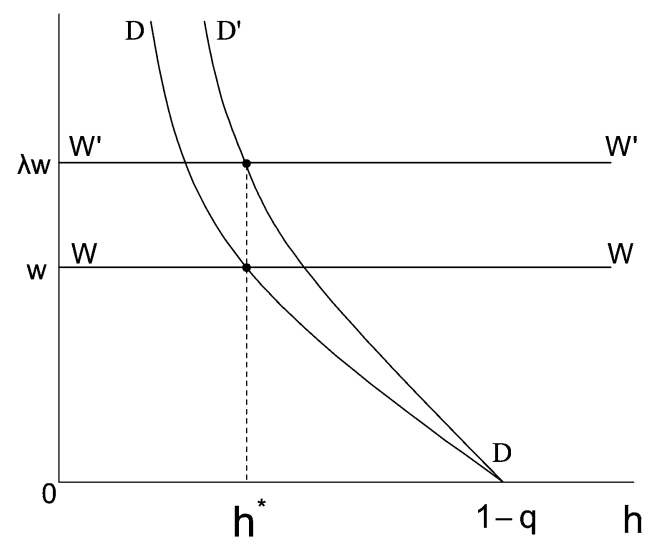

Figure 10. The effect of an increase in wages on time spent on housework.

Therefore, the demand curve for housework will shift down or up depending upon whether labor and capital are substitutes $(\kappa>0)$ or complements $(\kappa<0)$ in home production. Figure 9 portrays the case where labor and capital are substitutes.

Now, let wages jump up by a factor of $\lambda$. It is easy to deduce that the WW and DD curves will also shift up by a factor of $\lambda$ to $\mathrm{W}^{\prime} \mathrm{W}^{\prime}$ and $\mathrm{D}^{\prime} \mathrm{D}$, as is shown in Figure 10. Hence, the equilibrium level of housework remains unaffected. With logarithmic preferences an increase in wages by a factor of $\lambda$ will cause the consumption of market goods to increase by the same factor, which leads in turn to an equiproportionate rise in the relative price of home goods. Therefore, the value of marginal product curve shifts up by the factor $\lambda$.

EXAMPLE 5 (Female labor-force participation, 1900 and 1980). Assume the following parameter values.

(i) Tastes: $\beta=0.94^{20}$.

(ii) Technology: $\theta=0.33, \kappa=0.5, q=0$.

In 1900 about 5 percent of married white females worked. Assume that none did. There are about 224 nonsleeping hours available per couple in a week. If males worked a 40 hour week then $1-h=40 / 224=0.18$ in 1900 . Now, suppose that the amount of household capital in 1900 is negligible; i.e., set $\delta=0$. By using (45) it can be calculated that a value of $\mu=0.145$ is need to generate $1-h=0.18$. Next, about 50 percent of white married women worked in 1980. Therefore, $1-h=60 / 224=0.27$. From (45) it can be deduced that this value for $1-h$ can be obtained by setting $\delta=1.41$. Thus, a rise in female labor-force participation from zero to 50 percent can be generated by letting $\delta$ increase from 0 to 1.41 .

A technology adoption decision. Now suppose that the household faces a choice between two household production technologies, namely a new versus an old one. Rep- 
resent the new technology by the pair $\left(\delta^{1}, q^{1}\right)$, and the old one by $\left(\delta^{2}, q^{2}\right)$. To make the problem interesting, assume that $\delta^{1}>\delta^{2}$ and $q^{1}>q^{2}$. The new technology offers more capital services but costs more. Characterizing the household's adoption decision is straightforward:

Adopt new technology if $U\left(w, r, \delta^{1}, q^{1}\right)>U\left(w, r, \delta^{2}, q^{2}\right)$,

Adopt old technology if $U\left(w, r, \delta^{1}, q^{1}\right)<U\left(w, r, \delta^{2}, q^{2}\right)$,

Adopt either technology if $U\left(w, r, \delta^{1}, q^{1}\right)=U\left(w, r, \delta^{2}, q^{2}\right)$.

LEMMA 6. When capital and labor are Edgeworth-Pareto substitutes in household production $(0<\kappa \leqslant 1)$, the adoption of a new household technology will be associated with a decline in the amount of time spent on housework.

PROOF. From Equation (45) it is easy to calculate that

$$
\frac{\mathrm{d} h}{\mathrm{~d} q}=-\frac{h\left[\theta \delta^{\kappa}+(1-\theta) h^{\kappa}\right]}{\left\{(1-q)\left[\theta \delta^{\kappa}+(1-\theta) h^{\kappa}\right]-\kappa(1-h-q) \theta \delta^{\kappa}\right\}}<0,
$$

where again the denominator is positive since $\kappa \leqslant 1$ and $(1-q) \geqslant(1-h-q)$. Second, it was already established in Lemma 5 that $\operatorname{sign}(\mathrm{d} h / \mathrm{d} \delta)=-\operatorname{sign}(\kappa)$. The result is now immediate since $q_{1}>q_{2}$ and $\delta_{1}>\delta_{2}$.

Often new technologies are prohibitively expensive when they are first introduced. Hence, they are not adopted initially. It is clear that there exists some threshold price, $q^{*}$, at which the household is indifferent between adopting the new technology or not. This price is defined by the equation

$$
U\left(w, r, \delta^{1}, q^{*}\right)=U\left(w, r, \delta^{2}, q^{2}\right)
$$

LEMMA 7. The threshold price $q^{*}$ exists and is unique. Above the price $q^{*}$ the household will prefer to use the old technology while below it they will adopt the new one.

ProOF. It is easy to deduce from (40) that

$$
\frac{\mathrm{d} U}{\mathrm{~d} q}=-\frac{\mu w}{c^{\mathrm{y}}}<0
$$

and

$$
\frac{\mathrm{d} U}{\mathrm{~d} \delta}=(1-\mu) \theta \delta^{\kappa-1}\left\{\frac{1}{\theta \delta^{\kappa}+(1-\theta) h^{\kappa}}+\frac{\beta}{\theta \delta^{\kappa}+(1-\theta)}\right\}>0 .
$$

Equation (47) implies that the threshold price must be unique and that the household will use the new technology for any price $q^{1}<q^{*}$ and the old one for any price $q^{1}>q^{*}$. It is also easy to establish that the price $q^{*}$ exits. Clearly when $q^{1}=q^{2}$ the household will choose the new technology, since $U\left(w, r, \delta^{1}, q^{2}\right)>U\left(w, r, \delta^{2}, q^{2}\right)$ by (48). Likewise, 


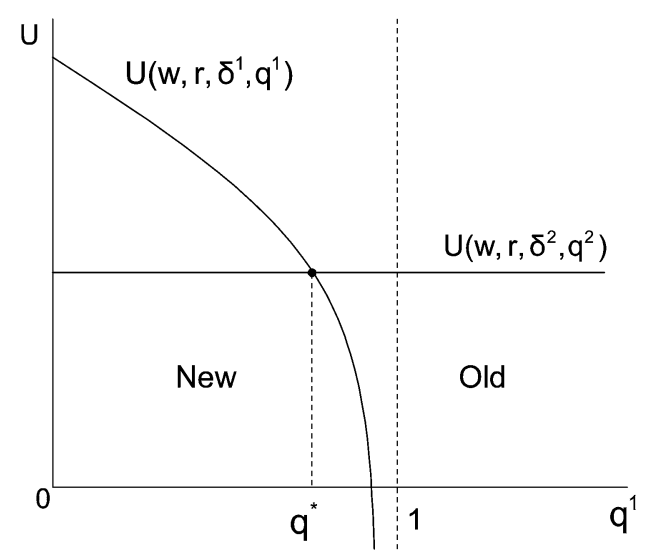

Figure 11. The determination of the threshold price, $q^{*}$.

$U\left(w, r, \delta^{1}, q^{1} \simeq 1\right)<U\left(w, r, \delta^{2}, q^{2}\right)$ for $q^{1}$ sufficiently close to one, since at this high price there will be no resources left over for market consumption. Hence, by the Intermediate Value Theorem the threshold price $q^{*}$ must exist.

The situation described by the lemma is portrayed in Figure 11. So long as the price for the new technology declines over time to the point $q^{*}$ households will eventually adopt it.

\subsection{Analysis with nondurable household products and services}

Over the last 100 years or so there has been a dramatic rise in the number of labor-saving nondurable household products and services. These goods and services economize on the need for housework. For example, in 1900 the bulk of baked goods, or 92 percent, was made at home. ${ }^{20}$ The average housewife is said to have baked more than $1 / 2$ ton of bread a year. She spent over 2 hours a week baking goods. ${ }^{21}$ By 1965 this had dropped to 22 percent. Similarly, 96 percent of vegetables purchased were unprocessed in 1900 , as opposed to 30 percent in $1965 .^{22}$ Per-capita consumption of canned fruits rose from 3.6 pounds in 1910 to 21.6 pounds in $1950 .^{23}$ Think of the time saved cleaning, pealing, canning, or otherwise preparing fruits and vegetables. There were about 2,100 packaged food products available in 1980, compared with 10,800 today. ${ }^{24}$ Last, in 1900

\footnotetext{
20 Source: Lebergott (1976, Table 1, p. 105).

21 Lebergott (1993, p. 81).

22 Again, see Lebergott (1976, Table 1, p. 105).

23 Source: "Historical Statistics of the United States: Colonial Times to 1970" [U.S. Bureau of the Census (1975, Series G 893)].

24 Source: Federal Reserve Bank of Dallas (1998, Exhibit 3, p. 6).
} 
only 5 percent of food expenditure was on meals away from home. This had risen to 30 percent by $1987 .{ }^{25}$ To explore how the introduction of new household products and services may promote female labor-force participation, a static model of the household will be presented.

Setup. For tastes take a static version of (39), so that utility is given by

$$
\mu \ln c+(1-\mu) \ln n,
$$

where $c$ and $n$ represent the individual's consumption of market and home goods, respectively. As before, the individual is endowed with one unit of time that he can use either for market work $1-h$, or housework $h$. Market work is compensated at the wage rate $w$. Home goods are produced in line with the household production function given below

$$
n=\left[\theta \sum_{i}^{N}\left(d_{i}\right)^{\kappa}+(1-\theta) h^{\kappa}\right]^{1 / \kappa} \quad \text { for } \kappa \leqslant 1,
$$

where $d_{i}$ denotes the agent's purchases of the $i$ th household product. Let the $i$ th household product sell at price $p_{i}$. There are $N$ products available.

The household's choice problem. The household's maximization problem is

$$
\max _{c,\left\{d_{i}\right\}_{i=1}^{N}, h, n}[\mu \ln c+(1-\mu) \ln n]
$$

subject to (50) and

$$
c+\sum_{i}^{N} p_{i} d_{i}=w(1-h)
$$

The first-order conditions for $d_{i}$ and $h$ can be written as

$$
\frac{\mu p_{i}}{c}=(1-\mu)\left[\theta \sum_{i}^{N}\left(d_{i}\right)^{\kappa}+(1-\theta) h^{\kappa}\right]^{-1} \theta d_{i}^{\kappa-1} \quad \text { for } i=1, \ldots, N
$$

and

$$
\frac{\mu w}{c}=(1-\mu)\left[\theta \sum_{i}^{N}\left(d_{i}\right)^{\kappa}+(1-\theta) h^{\kappa}\right]^{-1}(1-\theta) h^{\kappa-1} .
$$

It is immediate from (52) and (53) that

$$
\frac{\theta}{1-\theta}\left(\frac{d_{i}}{h}\right)^{\kappa-1}=\frac{p_{i}}{w}
$$


so that

$$
d_{i}=\left[\frac{(1-\theta) p_{i}}{\theta w}\right]^{1 /(\kappa-1)} h \equiv H_{i} h .
$$

Using this in (53), in conjunction with (51), yields a closed-form solution for $h$,

$$
h=\frac{(1-\mu)(1-\theta)}{\mu\left[\theta \sum_{i=1}^{N}\left(H_{i}\right)^{\kappa}+(1-\theta)\right]+(1-\mu)(1-\theta)\left(1+\sum_{i=1}^{N}\left(p_{i} / w\right) H_{i}\right)} .
$$

Analysis. The upshot of the above discussion is now within easy grasp.

LEMMA 8. An expansion in the number of household products and services, $N$, will cause housework, $h$, to decrease and market work, $1-h$, to increase.

PROOF. It is trivial to see that (54) is decreasing in $N$.

LeMma 9. A decline in the time price of the ith household product, $p_{i} / w$, will

(a) cause housework, $h$, to decline when intermediates goods and labor are Edgeworth-Pareto substitutes (or when $\kappa>0$ ),

(b) cause housework, $h$, to increase when intermediates goods and labor are Edgeworth-Pareto complements (or when $\kappa<0$ ),

(c) have no effect on housework, $h$, when intermediates goods and labor are neither Edgeworth-Pareto substitutes or complements (or when $\kappa=0$ ).

Proof. Observe that $H_{i}^{\kappa}$ and $\left(p_{i} / w\right) H_{i}$ are both decreasing or increasing in $p_{i} / w$ depending on whether $\kappa>0$ or $\kappa<0$. The results follow.

Given the form of tastes (49) and the household production function (50), an increase in the number of household products reduces the marginal product of housework (measured in utility terms). ${ }^{26}$ Hence, housework declines. Likewise, a decline in time price of household product $i$ will lead to its increased use. When intermediates goods and housework are Edgeworth-Pareto substitutes (complements) in utility this causes a fall (rise) in the marginal product of housework (again denoted in utility terms). Housework again drops.

\section{Conclusion}

Technological progress has profoundly reshaped the economic landscape over the last 200 years. It is easy to understand how the emergence of Watt's steam engine, Crompton's cotton spinning mule, and Cort's puddling and rolling process for iron transformed

26 I.e., the marginal product of housework multiplied by the marginal utility of home goods. 
the industrial landscape during the 1800 s. Likewise, it is easy to appreciate how the introduction of electricity, petrochemicals and the internal combustion engine changed manufacturing in the 1900s. Less well understood, however, is the impact that technological advance has had on the household sector. In 1800 the typical women labored in a rural home with 7 , largely uneducated, kids. Today she is almost certain to live in an urban area, likely to work in the market sector, and have only two children who on average get 13 years of formal schooling. Times have changed, and a little growth theory can go a long way toward understanding this process.

\section{Literature review}

\subsection{Fertility}

The economics literature on fertility starts with Malthus (1798). He believed that an economy's population had a natural size. This size was limited by the economy's fixed factors, in particular land. A society's population would increase, until its standard of living fell down to a subsistence level, reigning in further expansion. When an economy's population exceeded its natural size either poverty stricken parents would voluntarily reduce their family size or their family size would involuntarily decline due to famine induced disease.

Two classic papers on fertility in modern macroeconomics are by Razin and Ben-Zion (1975) and Becker and Barro (1988). The Razin and Ben-Zion (1975) model is similar to the setup presented in Section 2. They develop a small-open-economy overlappinggenerations model of fertility where kids simply enter their parents' utility function in the same way as other goods - say as in (1). The Becker and Barro (1988) model is more sophisticated, but harder to work with. It is an overlapping generations model, too, but now parents care about the utility of their children in addition to the number of kids. Since a parent cares about the happiness of his child who will in turn care about the happiness of his child (and so on, ad nauseam), the Becker and Barro (1988) model reformulates as an infinitely-lived representative agent model.

A milestone in the demographic transitions literature is a paper by Galor and Weil (2000). Over epochs of European history, fertility has followed a $\cap$-shaped pattern. Galor and Weil (2000) develop a model of this pattern by combining elements of Malthus (1798) and Razin and Ben-Zion (1975). They also allow for a human capital decision in the spirit of Becker and Tomes (1986). In addition they make two key assumptions: first, technological progress is an increasing function of population size, and second, the return on education rises with the rate of technological advance. In their framework, the world rests in a Malthusian equilibrium for a long time. Per-capita income remains more or less constant over time. All increases in aggregate income induced by technological progress are absorbed by expansions in the population. As the population slowly grows bigger, the pace of technological progress begins to pick up 
and the economy exits the Malthusian regime. At first parents use the extra income generated by technological advance to have more kids, since the return on education is still low. As the rate of technological progress accelerates the return to education rises, and parents choose to have fewer kids but invest more in them. ${ }^{27}$

A calibrated model that delivers a transition from Malthusian stagnation to growth, accompanied by a demographic transition from high to low fertility is presented in Doepke (2004). The engine in his analysis is a Becker and Barro (1988) style model modified to allow for parental human capital investment in children. He uses the model to study the role of social policies in shaping the demographic transition of a country more on this later.

Fernandez-Villaverde (2001) examines the ability of technological advance to explain, quantitatively, the fall in British fertility. He uses a variant of the Becker and Barro (1988) and Becker and Tomes (1986) frameworks to do this. In his analysis capital and skilled labor are complements in production. As the capital stock rises with economic development, this creates an impetus for parents to substitute away from having a large number of uneducated children toward having a small number of educated ones.

Little work has been done on the underlying cause of the baby boom. The best known hypothesis is by Easterlin (1987). The generation that spawned the baby boom grew up during the hard times of the Great Depression and World War II. As a result, this generation had low material aspirations. They then entered the work force in the 1940s and 1950s, a good time economically speaking. Given their low material aspirations, they used family formation as an outlet for their earnings. This hypothesis is empirically flawed on several grounds. ${ }^{28}$ First, there was no break in the trend for fertility during the Great Depression. Second, fertility in many OECD countries started to rise before the start of World War II. Third, at the peak of the baby boom (1960) the most fertile cohort of women (those in the 20 to 24 year old age group) were simply too young for either the Great Depression or World War II to have had much of an impact on them they were not alive during the Great Depression and were less than 9 years old at the end of World War II.

\subsection{The economics of household production}

The economic importance of household production was probably first recognized in a classic book by Reid (1934). Reid (1934, p. v) felt that "the productive work of the household has been overlooked, even though more workers are engaged in it than any

27 Often the drop in fertility is attributed to a decline in child mortality. In some countries, such as the France and the U.S., the decline in fertility proceeded the drop in child mortality. Doepke (2005) argues within the context of a sequential fertility model with uncertainty about child mortality that the impact of a decline in child mortality is likely to be small. That is, if the issue is child mortality, why would a woman who already has some surviving children give birth to yet more children as is observed in the data.

28 The Easterlin hypothesis is critiqued in Greenwood, Seshadri and Vandenbroucke (2005). 
other single industry". She carefully reported and analyzed the uses of time and capital by households of the era. The data was fragmentary then, and sadly still is. Reid (1934) knew in theory that labor-saving household capital could reduce the amount of time spent on housework, but the just emerging evidence at the time suggested that this effect was modest (see Table XIII, p. 91).

In a famous paper Becker (1965) develops the modern approach to household production: the treatment of the household as a small factory or plant using inputs, such as labor, capital and raw materials, to produce some sort of home goods. This is the notion underlying the household production functions (2) and (42) used in Sections 2 and 5. Benhabib, Rogerson and Wright (1991) introduce household production theory into a dynamic general equilibrium model in order to study the movement of labor over the business cycle. The idea is that in favorable economic times households may temporarily move labor out of the home sector to take advantage of good market opportunities, thereby increasing the elasticity of labor supply. Parente, Rogerson and Wright (2000) use a similar framework to investigate whether household production can explain cross-country income differentials. This is very much in the spirit of Reid (1934, pp. 165-166), who observed that the "(g)oods resulting from household production receive no market valuation...". She reports (p. 167) an estimate placing the value of housewives' services at $\$ 15.3$ billion in 1918 compared with a national income of $\$ 61$ billion. Last, Rios-Rull (1993) inserts household production into an overlapping generations model to examine its impact on the time allocations of skilled versus unskilled labor. In his framework, skilled labor (relative to unskilled labor) will tend to substitute market goods or services for labor in household production.

\subsection{Structural change}

Two well-known models of structural change have been developed by Echevarria (1997) and Laitner (2000). Laitner (2000) presents a closed-economy model with two sectors, viz agriculture and manufacturing. Two key features of the analysis are that the demand for agricultural goods has a zero income elasticity after a certain consumption level, and that production in the agricultural sector is subject to technological progress. As the state of technology advances in the agricultural sector less labor is required to satisfy the fixed demand for agricultural goods. Echevarria (1997) develops a more general three-sector model, which she solves numerically. Restrictions on tastes and technologies that allow for tractable solutions to models with structural change are developed in Kongsamut, Rebelo and Xie (2001). Caselli and Coleman (2001) study the process of regional convergence in the U.S. between the agricultural South and manufacturing North. They argue that declining costs of education, which allow the skills essential for manufacturing to be picked up more easily, play an important role in explaining the pattern of convergence in wages between the South and North. In particular, this latter feature allows convergence to obtain without a fall (in fact with a rise) in farm, relative to nonfarm, wages. Last, in Western economies there has been a secular shift in employment out of manufacturing into services. The growth of the service sector in 
several European countries, however, has been encumbered by institutional rigidities. These services have been provided by the household sector instead. This phenomena is analyzed by Rogerson (2002).

Now, the model presented in Section 3 has a single good that can be produced by one or both of two sectors, interpreted as agriculture and manufacturing. The pace of technological progress is assumed to be faster in the latter sector. This draws labor into manufacturing. A similar assumption is made in Hansen and Prescott (2002) who model the transition from the pre-industrial to the modern era. Grafted onto the model developed in Section 3 is a fertility decision à la Razin and Ben-Zion (1975). Also overlaid onto the framework is a human capital decision along the lines of Becker and Tomes (1986). Here parents care about the earnings that their kids will make, as in the Galor and Weil (2000) framework, as opposed to the level of their human capital see (17).

It is easy to modify the framework developed in Section 3 to allow for two types of goods in tastes, agricultural and manufactured. By endowing agricultural goods with a lower income elasticity than manufactured ones an extra channel for structural change can be added. ${ }^{29}$ In fact, a similar device is already employed in the model of the baby bust and baby boom in Section 2. Observe that the term $\mathfrak{c}>0$ in (1) operates to lower the income elasticity of children relative to market goods. As income rises a parent switches resources away from children toward the consumption of market goods. [Interestingly, Jones (2001) sets $\mathfrak{c}<0$. This raises the income elasticity of children relative to market goods. Hence, fertility will be low when a person is poor. Jones (2001) uses this to generate the left-hand side of the $\cap$-shaped pattern in fertility. The right-hand side obtains by assuming an isoelastic utility function in consumption, $(c+\mathfrak{c})^{\rho} / \rho$ (for $\rho \leqslant 1$, that is less curved than $\ln (c+c)$ in $c+\mathfrak{c}$; i.e., by picking $\rho>0 .{ }^{30}$ Therefore, at high levels of income, as income rises the marginal utility of consumption falls slower than the marginal utility of kids. This generates a decline in fertility.]

\subsection{Child labor}

Both demographers and economists have long stressed the economic value of children in societies. Adam Smith (1973, p. 173) said, when speaking of colonial America:

Labour there is so well rewarded that a numerous family of children, instead of being a burden, is a source of opulence and prosperity to the parents. The labour of each child, before it can leave their house, is computed to be worth a hundred pounds clear gain to them.

Likewise Gary Becker (1960, p. 213) states:

29 The interested reader can see Greenwood and Seshadri (2002).

30 See also Greenwood and Seshadri (2002). 
It is possible that in the mid-nineteenth century children were a net producer's good, providing rather than using income.

Noted demographer John Caldwell (1982) has argued that there are two types of societies: pre-transitional and post-transitional. The former are characterized by net flows from children to parents while the latter are characterized by net flows in the opposite direction - some of the flows from children to parents may be in the form old-age support for the latter. [For an application of the Caldwell hypothesis to the demographic transition literature, see Boldrin and Jones (2002).]

Now suppose that the net present value of a kid is positive and that the prime motivation for having children is wealth maximization. Then fertility rates should be close to their biological maximum. This does not seem to have been observed. While children undoubtedly made important contributions to the family income, as these quotes attest, most historical research suggests that it would have been very unlikely that the net present value of children could have been positive. Economic historian Nardinelli (1990) presents a comprehensive review of the literature on the cost of children and argues that it is extremely unlikely that children were capital goods. Economic demographer Mueller (1976) has shown that even under the most plausible assumptions, the net worth of children in peasant societies is negative and concludes "(i)n sum, the aggregate model and the life-cycle model agree in showing that children have negative economic value in peasant agriculture" (p. 145). The huge literature on slavery provides a clearer picture on the productivity of child labor in preindustrial societies. Fogel and Engerman (1974, p. 153) report that "prior to age twenty-six, the accumulated expenditures by planters on slaves were greater than the average accumulated income which they took from them". While critics have questioned their estimated rates of return, even higher estimates do not make children profitable in the short run. And surely if slave children had negative net worth, it seems likely that free children in agricultural societies would have had negative value. The basic problem is that children can earn very little for the first decade or so of their lives. Yet, they must be maintained. Discounting makes it difficult to overcome the front-end costs of raising children. ${ }^{31}$

Now, even if the net-present value of a child's earnings to his parents is negative the possibility of child labor may significantly defray the cost of bearing him or increase the cost of educating him - as is evident from the first-order condition (34). As such, it can still have a big influence on an adult's fertility decision, as well as on a parent's decision about educating his child. Doepke (2004) examines the impact that child labor laws and educational subsidies may have on fertility and growth - note that compulsory schooling laws can effectively limit child labor as well as subsidize schooling. Both policies operate to promote a higher level of human capital investment and faster fertility decline. Surprisingly, ruling out child labor turns out to be much more effective than subsidizing education in speeding up the demographic transition from high to low

31 Still, if there is no good abode for savings in a society, then children may be better than nothing in providing for old age. 
fertility. Hazan and Berdugo (2002) also argue that outlawing child labor expedites this transition process.

Last, in the model presented in Section 4 a rise in the demand for skilled labor leads to a decline in the use of child labor. If family size was variable, as in Section 3, then smaller families would result too. Doepke and Zilibotti (2003) use this mechanism to model the enactment of child labor laws as a country develops. Child labor substitutes in production for unskilled adult labor. Therefore, on this hand, unskilled adult labor gains from outlawing child labor. On the other hand, unskilled adults will earn income by letting their children work. At early stages of economic development most adults will be unskilled and families will be large. There will not be much support for child labor laws. Now, suppose that the return to skill rises over time due to economic development. As more and more unskilled families choose to have fewer children, and to educate them, the political equilibrium shifts to favoring a ban on child labor.

\subsection{Female labor-force participation}

The economic analysis of female labor-force participation began with the pioneering works of Mincer (1962) and Cain (1966). The massive rise in female labor-force participation over the course of the twentieth century has attracted a lot of notice from labor economists. Much attention has been devoted to examining the extent to which the rise in real wages and the narrowing of the gender gap can account for the rise in laborforce participation. The narrowing of the gender gap has been analyzed by Blau and Kahn (2000) and Goldin (1990). Galor and Weil (1996) provide an interesting general equilibrium model in which the increase in women's wages and labor-force participation is a by-product of the process of development where capital accumulation raises women's wages relative to men's wages. The underlying mechanism is that capital is more complementary to women's labor than it is to men's labor. Consequently capital accumulation will lead to greater increases in women's wages than men's wages. In a similar vein, Jones, Manuelli and McGrattan (2003) argue that decreases in the gender wage gap can account for increases in average hours worked by married females for the time period between 1950 and 1990.

It is easy to introduce the gender gap in the framework developed in Section 5. Recall that the model implies that a general increase in wages will have no effect on labor-force participation. This is proved in Lemma 5 and is easy to see from Equations (43) and (44). A rise in $w$ will lead to an equiproportionate increase in $c^{\mathrm{y}}$ and hence will have no impact on $h$. Now suppose Equation (41) is changed to read

$$
c^{\mathrm{y}}+\frac{c^{\mathrm{o} \prime}}{r}=0.5 w+\phi w(0.5-h)-w q .
$$

Here $\phi$ represents the gender gap, or the ratio of female to male wages. Males and females each have a time endowment of 0.5. Males are presumed always to work full time. Females can vary their market labor supply, $0.5-h$. The efficiency condition for $h$ will once again be given by (43), but now the left-hand side will be multiplied by $\phi$. It 
is easy to deduce that an increase in $\phi$ will lead to an increase in $h$, since $c^{\mathrm{y}}$ will rise by less than $\phi{ }^{32}$ Observe that unlike the Galor and Weil (1996) setup, but like the Jones, Manuelli and McGrattan (2003) one, the gender gap is taken to be exogenous.

Empirically speaking, the gender gap did not move much between 1930 and 1980 . More specifically, data from Blau and Kahn (2000) suggest that between 1955 and 1980, the period associated with enormous increases in the labor force participation rate, the gap remained almost constant. ${ }^{33}$ In 1969, the female-to-male weekly wage ratio was 0.56 and this number rose merely to 0.58 by 1979 [see Blau (1998, Table 4, p. 129)]. Unless labor supply elasticities for women are quite high, the narrowing down of the gender gap can only be a small part of the explanation. Additionally, the gender gap may have narrowed dramatically between 1820 and 1880 [Goldin (1987, Figure 3, p. 215)] with probably little rise in married female labor-force participation (given the very low rate in 1890). All of this suggests that something else was going on, in addition to the narrowing of the gender gap, which led women to enter the labor force, such as the introduction of labor-saving household goods. On this, perhaps the introduction of such goods increased the elasticity of female labor supply. Intriguingly, the data suggest that for the 1900-1930 period married women's uncompensated wage elasticities of labor-force participation were close to zero, while in the middle of the century women's uncompensated wage elasticities were quite high - as high as 1.5 in some studies. ${ }^{34}$

An interesting and related development fact is that female labor-force participation is U shaped over the course of economic development - see Goldin (1995). The U-shaped pattern is very prominent in the cross-section. She believes that the trough of the $\mathrm{U}$ for the U.S. was reached around 1920. A simple modification of the model introduced in Section 5 can be used to account for the U shape. Imagine adding a subsistence consumption constraint. When incomes are very low and consumption is below subsistence, women go out to work in order to achieve the subsistence level of consumption. As incomes rise with technological advance in the market sector, the income effect associated with easing the subsistence constraint dominates the substitution effect (holding fixed the household production function) and time spent in the paid labor force decreases. In other words, the declining portion of the U associated with the pre-1920 era can be accounted for. After 1920 the introduction of labor-saving appliances associated with technological progress in the home sector could have led to more women entering into the workforce. Thus, growth theory can go a long way toward accounting for the entire time path of married female labor-force participation over the course of economic development.

32 Note that Equation (44) will change to

$$
c^{\mathrm{y}}=\frac{w[0.5+\phi(0.5-h)-q]}{1+\beta} .
$$

33 In fact the gender pay gap increased between 1955 and 1968 [see Blau and Kahn (2000, Figure 1, p. 76)]. The gender gap did narrow considerably in the period after 1980 .

34 See Goldin (1990, Table 5.2, p. 132). 
There are other explanations of the rise in female labor-force participation. The effect of World War II has received some attention, for instance. Goldin (1991) investigates the effects of World War II on women's labor-force participation and finds that a little over half of the women who entered the labor market during the war years exited by 1950. Another possibility is that attitudes toward working women might have changed considerably and this encouraged women to enter into the paid labor force. While this is hard to know, one can look at social surveys across time to gain a better understanding. After reviewing public opinion poll evidence, Oppenheimer (1970, p. 51) concludes "it seems unlikely that we can attribute much of the enormous postwar increases in married women's labor force participation to a change in attitudes about the propriety of their working". On this, Fernandez, Fogli and Olivetti (2004) present evidence suggesting that a man is more likely to have a working wife if his own mother worked than if she did not. In particular, men who had mothers who worked in World War II had a higher likelihood of marrying working women than those who did not. They develop a model where attitudes toward working women become more receptive over time. This idea complements those set out in Section 5. The famous sociologist William F. Ogburn hypothesized that culture and social institutions evolve, often with a lag, to technological progress in the economy (or presumably to other events such as wars). Ogburn (1965, p. 85) said:

Unlike the natural environment, the technological environment is a huge mass in rapid motion. It is no wonder then that our society with its numerous institutions and organizations has an almost impossible task in adjusting to this whirling technological environment. It should be no surprise to sociologists that the various forms and shapes which our social institutions take and the many shifts in their function are the result of adjustments - not to a changing natural environment, not to a changing biological heritage - but to adaptations to a changing technology.

\section{Acknowledgements}

Matthias Doepke, Nezih Guner and Baris Kaymak are thanked for comments. Financial support from the NSF (award number 0136055) is gratefully acknowledged.

\section{Appendix:}

\section{A.1: Supporting calculations for Lemmas 2 and 4}

$$
\begin{aligned}
\frac{\partial n}{\partial(z / x)}=\frac{\chi}{\psi+\chi}\{ & -\frac{\left[1+\omega(z / x)^{1 /(\sigma-1)}\right](1 /(\sigma-1)) \tau \omega(z / x)^{1 /(\sigma-1)-1}}{\left[\tau+\phi+\tau \omega(z / x)^{1 /(\sigma-1)}\right]^{2}} \\
& \left.+\frac{\omega(z / x)^{1 /(\sigma-1)-1}(1 /(\sigma-1))}{\left[\tau+\phi+\tau \omega(z / x)^{1 /(\sigma-1)}\right]}\right\}
\end{aligned}
$$




$$
\begin{aligned}
= & \frac{\chi}{\psi+\chi} \frac{1}{\left[\tau+\phi+\tau \omega(z / x)^{1 /(\sigma-1)}\right]^{2}} \frac{\omega}{\sigma-1}(z / x)^{1 /(\sigma-1)-1} \\
& \times\left\{-\left[1+\omega(z / x)^{1 /(\sigma-1)}\right] \tau+\left[\tau+\phi+\tau \omega(z / x)^{1 /(\sigma-1)}\right]\right\} \\
= & \frac{\chi}{\psi+\chi} \frac{1}{\left[\tau+\phi+\tau \omega(z / x)^{1 /(\sigma-1)}\right]^{2}} \frac{\phi \omega}{\sigma-1}(z / x)^{1 /(\sigma-1)-1} .
\end{aligned}
$$

$$
\begin{aligned}
\frac{\partial^{2} n}{\partial(z / x)^{2}}= & \frac{\chi}{\psi+\chi} \frac{\phi \omega}{\sigma-1} \\
& \times\left\{-\frac{2}{\sigma-1} \frac{1}{\left[\tau+\phi+\tau \omega(z / x)^{1 /(\sigma-1)}\right]^{3}}\right. \\
& \times(z / x)^{1 /(\sigma-1)-1} \tau \omega(z / x)^{1 /(\sigma-1)-1} \\
& \left.+\left(\frac{1}{\sigma-1}-1\right) \frac{1}{\left[\tau+\phi+\tau \omega(z / x)^{1 /(\sigma-1)}\right]^{2}}(z / x)^{1 /(\sigma-1)-2}\right\} \\
= & \frac{\chi}{\psi+\chi} \frac{\phi \omega}{\sigma-1} \frac{1}{\left[\tau+\phi+\tau \omega(z / x)^{1 /(\sigma-1)}\right]^{3}}(z / x)^{1 /(\sigma-1)-2} \\
& \times\left\{-\frac{2}{(\sigma-1)} \tau \omega(z / x)^{1 /(\sigma-1)}+\frac{2-\sigma}{\sigma-1}\left[\tau+\phi+\tau \omega(z / x)^{1 /(\sigma-1)}\right]\right\} \\
= & \frac{\chi}{\psi+\chi} \frac{\phi \omega}{\sigma-1} \frac{1}{\sigma-1} \frac{1}{\left[\tau+\phi+\tau \omega(z / x)^{1 /(\sigma-1)}\right]^{3}}(z / x)^{1 /(\sigma-1)-2} \\
& \times\left\{(2-\sigma)(\tau+\phi)-\sigma \tau \omega(z / x)^{1 /(\sigma-1)}\right\} .
\end{aligned}
$$

$$
\frac{\partial h}{\partial(z / x)}=\frac{1}{\left[1+\omega(z / x)^{1 /(\sigma-1)}\right]^{2}} \frac{\omega}{1-\sigma}(z / x)^{1 /(\sigma-1)-1} .
$$

$$
\begin{aligned}
\frac{\partial^{2} h}{\partial(z / x)^{2}}= & \frac{\omega}{1-\sigma}\left\{-\frac{2}{\left[1+\omega(z / x)^{1 /(\sigma-1)}\right]^{3}}(z / x)^{1 /(\sigma-1)-1} \frac{1}{\sigma-1} \omega(z / x)^{1 /(\sigma-1)-1}\right. \\
& \left.\quad+\frac{1}{\left[1+\omega(z / x)^{1 /(\sigma-1)}\right]^{2}}\left(\frac{2-\sigma}{\sigma-1}\right)(z / x)^{1 /(\sigma-1)-2}\right\} \\
= & \frac{\omega}{1-\sigma} \frac{1}{\sigma-1} \frac{1}{\left[1+\omega(z / x)^{1 /(\sigma-1)}\right]^{3}}(z / x)^{1 /(\sigma-1)-2} \\
& \times\left\{-2 \omega(z / x)^{1 /(\sigma-1)}+(2-\sigma)\left[1+\omega(z / x)^{1 /(\sigma-1)}\right]\right\} \\
= & \frac{\omega}{1-\sigma} \frac{1}{\sigma-1} \frac{1}{\left[1+\omega(z / x)^{1 /(\sigma-1)}\right]^{3}}(z / x)^{1 /(\sigma-1)-2} \\
& \times\left\{2-\sigma-\sigma \omega(z / x)^{1 /(\sigma-1)}\right\} .
\end{aligned}
$$




\section{A.2: Supporting calculations for Lemmas 5 and 6}

Write Equation (45) as

$$
1=\Psi \frac{(1-h)-q}{\left[\theta \delta^{\kappa}+(1-\theta) h^{\kappa}\right]} h^{\kappa-1},
$$

where

$$
\Psi=\frac{(1-\theta)(1-\mu)}{\mu(1+\beta)} .
$$

From this it is easy to compute that

$$
\begin{aligned}
\frac{\mathrm{d} h}{\mathrm{~d} \delta}= & \kappa \Psi \frac{(1-h)-q}{\left[\theta \delta^{\kappa}+(1-\theta) h^{\kappa}\right]^{2}} h^{\kappa-1} \theta \delta^{\kappa-1} \\
\times & \left\{\Psi \frac{1}{\left[\theta \delta^{\kappa}+(1-\theta) h^{\kappa}\right]} h^{\kappa-1}+\Psi \frac{(1-h)-q}{\left[\theta \delta^{\kappa}+(1-\theta) h^{\kappa}\right]^{2}} \kappa h^{\kappa-1}(1-\theta) h^{\kappa-1}\right. \\
& \left.\quad-\Psi \frac{(1-h)-q}{\left[\theta \delta^{\kappa}+(1-\theta) h^{\kappa}\right]}(\kappa-1) h^{\kappa-2}\right\}^{-1} \\
=- & \kappa[(1-h)-q] h^{\kappa-1} \theta \delta^{\kappa-1} \\
& \times\left\{\left[\theta \delta^{\kappa}+(1-\theta) h^{\kappa}\right] h^{\kappa-1}+[(1-h)-q] \kappa h^{\kappa-1}(1-\theta) h^{\kappa-1}\right. \\
& \left.\quad-[(1-h)-q]\left[\theta \delta^{\kappa}+(1-\theta) h^{\kappa}\right](\kappa-1) h^{\kappa-2}\right\}^{-1} \\
= & \kappa[(1-h)-q] h^{\kappa-1} \theta \delta^{\kappa-1} \\
& \times\left\{\left[\theta \delta^{\kappa}+(1-\theta) h^{\kappa}\right] h^{\kappa-1}-[(1-h)-q] \theta \delta^{\kappa}(\kappa-1) h^{\kappa-2}\right. \\
& \left.+[(1-h)-q](1-\theta) h^{2 \kappa-2}\right\}^{-1} \\
= & \kappa[(1-h)-q] h \theta \delta^{\kappa-1} \\
& \times\left\{\left[\theta \delta^{\kappa}+(1-\theta) h^{\kappa}\right] h+[(1-h)-q] \theta \delta^{\kappa}(1-\kappa)\right. \\
& \left.\quad+[(1-h)-q](1-\theta) h^{\kappa}\right\}^{-1} \\
= & \kappa \frac{[(1-h)-q] h \theta \delta^{\kappa-1}}{\left\{(1-q)\left[\theta \delta^{\kappa}+(1-\theta) h^{\kappa}\right]-\kappa(1-h-q) \theta \delta^{\kappa}\right\}} .
\end{aligned}
$$

Clearly, the denominator of the above expression is always positive, since $1-q \geqslant$ $1-h-q$ and $\kappa \leqslant 1$. Therefore

$$
\operatorname{sign}\left(\frac{\mathrm{d} h}{\mathrm{~d} \delta}\right)=-\operatorname{sign}(\kappa)
$$

Likewise, it is easy to calculate that

$$
\frac{\mathrm{d} h}{\mathrm{~d} q}=-\frac{h\left[\theta \delta^{\kappa}+(1-\theta) h^{\kappa}\right]}{\left\{(1-q)\left[\theta \delta^{\kappa}+(1-\theta) h^{\kappa}\right]-\kappa(1-h-q) \theta \delta^{\kappa}\right\}}<0,
$$

where again the denominator of the above expression is always positive, since $1-q \geqslant$ $1-h-q$ and $\kappa \leqslant 1$. 


\section{References}

Becker, G.S. (1960). "An economic analysis of fertility". In: A Report of the National Bureau of Economic Research, Demographic and Economic Change in Developed Countries: A Conference of the Universities-National Bureau Committee for Economic Research. Princeton University Press, Princeton, NJ, pp. 209-231.

Becker, G.S. (1965). "A theory of the allocation of time”. Economic Journal 75 (299), 493-517.

Becker, G.S., Barro, R.J. (1988). "A reformulation of the economic theory of fertility”. The Quarterly Journal of Economics 103 (1), 1-25.

Becker, G.S., Tomes, N. (1986). "Human capital and the rise and fall of families". Journal of Labor Economics 4 (3), part 2, S1-S39.

Benhabib, J., Rogerson, R., Wright, R. (1991). "Homework in macroeconomics: Household production and aggregate fluctuations". Journal of Political Economy 99 (6), 1166-1187.

Blau, F.D. (1998). "Trends in the well-being of American women, 1970-1995”. Journal of Economic Literature $36(1), 112-165$.

Blau, F.D., Kahn, L.M. (2000). "Gender differences in pay”. The Journal of Economic Perspectives 14 (4), 75-99.

Boldrin, M., Jones, L.E. (2002). "Mortality, fertility and savings in a Malthusian economy". Review of Economic Dynamics 5 (4), 775-814.

Cain, G.G. (1966). Married Women in the Labor Force: An Economic Analysis. University of Chicago Press, Chicago.

Caldwell, J.C. (1982). Theory of Fertility Decline. Academic Press, London.

Caplow, T., Hicks, L., Wattenberg, B.J. (2001). The First Measured Century: An Illustrated Guide to Trends in America, 1900-2000. The AEI Press, Washington, DC.

Caselli, F., Coleman II, W.J. (2001). "The U.S. structural transformation and regional convergence: A reinterpretation". Journal of Political Economy 109 (3), 585-616.

Doepke, M. (2004). "Accounting for fertility decline during the transition to growth". Journal of Economic Growth 9 (3), 347-383.

Doepke, M. (2005). "Child mortality and fertility decline: Does the Barro-Becker model fit the facts?". Journal of Population Economics 18 (2), in press.

Doepke, M., Zilibotti, F. (2003). "Macroeconomics of child labor regulation". Staff Report 354. Federal Reserve Bank of Minneapolis, submited for publication in American Economic Review.

Easterlin, R.A. (1987). "Easterlin hypothesis". In: Eatwell, J., Milgate, M., Newman, P. (Eds.), The New Palgrave: A Dictionary of Economics, vol. 2. Macmillan Press Ltd, London, pp. 1-4.

Echevarria, C. (1997). "Changes in sectoral composition associated with economic growth". International Economic Review 38 (2), 431-452.

Eisenberg, M.J. (1988). “Compulsory attendance legislation in America, 1870-1915”. Unpublished Ph.D. Dissertation. Department of Economics, University of Pennsylvania.

Federal Reserve Bank of Dallas (1998). The Right Stuff: America's Move to Mass Customization. 1998 Annual Report. Federal Reserve Bank of Dallas, Dallas, TX.

Fernandez-Villaverde, J. (2001). "Was Malthus right? Economic growth and population dynamics". Unpublished Paper. Department of Economics, University of Pennsylvania.

Fernandez, R., Fogli, A., Olivetti, C. (2004). "Mothers and sons: Preference formation and female labor force dynamics". The Quarterly Journal of Economics 119 (4), 1249-1299.

Fogel, R.W., Engerman, S.L. (1974). Time on the Cross: The Economics of American Negro Slavery. Little, Brown and Company, Boston.

Galor, O., Weil, D.N. (1996). “The gender gap, fertility, and growth”. American Economic Review 86 (3), 374-387.

Galor, O., Weil, D.N. (2000). "Population, technology and growth: From Malthusian stagnation to the demographic transition and beyond". American Economic Review 90 (4), 806-828. 
Goldin, C. (1987). “Women's Employment and Technological Change: A Historical Perspective". In: Hartmann, H. (Ed.), Computer Chips and Paper Clips: Technology and Women's Employment, vol. II. National Academy Press, Washington, DC, pp. 185-222.

Goldin, C. (1990). Understanding the Gender Gap: An Economic History of American Women. Oxford University Press, New York.

Goldin, C. (1991). "The role of World War II in the rise of women's employment". American Economic Review 81 (4), 741-756.

Goldin, C. (1995). "The U-shaped female labor force function in economic development and economic history". In: Schultz, T.P. (Ed.), Investment in Women's Human Capital and Economic Development. University of Chicago Press, Chicago, pp. 61-90.

Greenwood, J., Seshadri, A. (2002). "The U.S. demographic transition”. American Economic Review (Papers and Proceedings) 92 (2), 153-159.

Greenwood, J., Seshadri, A., Vandenbroucke, G. (2005). "The baby boom and baby bust". American Economic Review 95 (1), 183-207.

Greenwood, J., Seshadri, A., Yorukoglu, M. (2005). "Engines of liberation”. Review of Economic Studies 72 (1), 109-133.

Hansen, G., Prescott, E.C. (2002). "Malthus to Solow”. American Economic Review 92 (4), 1205-1217.

Hazan, M., Berdugo, B. (2002). "Child labor, fertility, and economic growth". The Economic Journal 112 (482), 810-828.

Jones, C.I. (2001). "Was an industrial revolution inevitable? Economic growth over the very long run". Advances in Macroeconomics 1 (2), Article 1.

Jones, L., Manuelli, R.E., McGrattan, E. (2003). "Why are married women working so much?". Research Department Staff Report 317. Federal Reserve Bank of Minneapolis.

Kongsamut, P., Rebelo, S.T., Xie, D. (2001). "Beyond Balanced Growth". Review of Economic Studies 68 (4), 869-882.

Laitner, J. (2000). "Structural change and economic growth”. Review of Economic Studies 67 (3), 545-561.

Landes, W., Solmon, L. (1972). "Compulsory schooling legislation: An economic analysis of law and social change in the nineteenth century". Journal of Economic History 32 (1), 54-91.

Lebergott, S. (1964). Manpower in Economic Growth: The American Record Since 1800. McGraw-Hill Book Company, New York.

Lebergott, S. (1976). The American Economy: Income, Wealth and Want. Princeton University Press, Princeton, NJ.

Lebergott, S. (1993). Pursuing Happiness: American Consumers in the Twentieth Century. Princeton University Press, Princeton, NJ.

Malthus, T.R. (1798). An Essay on the Principle of Population as It Affects the Future Improvement of Society with Remarks on the Speculations of Mr. Godwin, M. Condorcet, and Other Writers. J. Johnson, London.

Margo, R.A., Finegan, T.A. (1996). "Compulsory schooling legislation and school attendance in turn-of-thecentury America: A "Natural Experiment” approach”. Economic Letters 53 (1), 103-110.

Mincer, J. (1962). "Labor force participation of married women: A study of labor supply". In: Lewis, G.H. (Ed.), Aspects of Labor Economics: A conference of the Universities-National Bureau Committee for Economic Research. Princeton University Press, Princeton, NJ, pp. 63-105.

Mueller, E. (1976). "The Economic Value of Children in Peasant Agriculture”. In: Ridker, R.G. (Ed.), Population and Development: The Search for Selective Interventions. Johns Hopkins University Press, Baltimore, pp. $98-153$.

Nardinelli, C. (1990). Child Labor and the Industrial Revolution. Indiana University Press, Bloomington.

Ogburn, W.F. (1965). “Technology as Environment”. In: Ogburn, W.F. (Ed.), On Cultural and Social Change: Selected Papers. The University of Chicago Press, Chicago, pp. 78-85.

Oppenheimer, V.K. (1970). The Female Labor Force in the United States: Demographic and Economic Factors Governing Its Growth and Changing Composition. Institute of International Studies University of California, Berkeley, CA.

Parente, S.L., Rogerson, R., Wright, R. (2000). "Homework in development economics: Household production and the Wealth of Nations". Journal of Political Economy 108 (4), 680-687. 
Ramsey, F.P. (1928). “A mathematical theory of savings”. Economic Journal 38 (152), 543-559.

Razin, A., Ben-Zion, U. (1975). "An intergenerational model of population growth". American Economic Review 65 (5), 923-933.

Reid, M.G. (1934). Economics of Household Production. John Wiley \& Sons Inc., New York.

Rios-Rull, J.-V. (1993). "Working in the market, working at home, and the acquisition of skills: A generalequilibrium approach". American Economic Review 83 (4), 893-907.

Rogerson, R. (2002). "The evolution of OECD employment, 1960-2000: The role of structural transformation". Unpublished Paper. Department of Economics, Arizona State University.

Smith, A. (1973). The Wealth of Nations. Penguin Books Ltd, Harmondsworth.

Solow, R.M. (1956). "A contribution to the theory of economic growth". The Quarterly Journal of Economics 70 (1), 65-94.

U.S. Bureau of the Census (1975). Historical Statistics of the United States: Colonial Times to 1970. U.S. Bureau of the Census, Washington, DC.

Zelizer, V.A. (1994). Pricing the Priceless Child: The Changing Social Value of Children. Princeton University Press, New York. 